\title{
Biological Movements Look Uniform: Evidence of Motor-Perceptual Interactions
}

\author{
Paolo Viviani and Natale Stucchi \\ Department of Psychobiology \\ Université de Genève, Geneva, Switzerland
}

\begin{abstract}
Six experiments demonstrate a visual dynamic illusion. Previous work has shown that in 2dimensional (2D) drawing movements, tangential velocity and radius of curvature covary in a constrained manner. The velocity of point stimuli is perceived as uniform if and only if this biological constraint is satisfied. The illusion is conspicuous: The variations of velocity in the stimuli exceed $200 \%$. Yet movements are perceived as uniform. Conversely, 2D stimuli moving at constant velocity are perceived as strongly nonuniform. The illusion is robust: Exposure to true constant velocity fails to suppress it. Results cannot be explained entirely by the kinetic depth effect. The illusion is evidence of a coupling between motor and perceptual processes: Even in the absence of any intention to perform a movement, certain properties of the motor system implicitly influence perceptual interpretation of the visual stimulus.
\end{abstract}

Many experimental facts can support the general view that visual percepts arise less as a direct, inescapable consequence of the sensory data than as the result of a selection process that is based on sensory cues and acts on a set of alternatives available a priori to the perceptual system. This view can be qualified in several different (logically independent and not mutually exclusive) ways, according to the hypothesis that one makes with regard to the selection process, the nature of the alternatives, and their ontogenesis. For example, it is well known that certain illusory phenomena (e.g., the size-constancy effect) have been explained by assuming that sensory data are interpreted within the framework of cognitive preconceptions about the properties of real objects (Coren \& Girgus, 1978a, 1978b). The best source of inspiration for theorists comes, however, from dynamic stimuli. For instance, a number of classical experiments have shown that certain classes of relative motions between simple figural elements (dots and lines) are consistently perceived in ways that do not correspond to the simplest interpretation of the sensory data. An example is provided by the situation in which two dots move sinusoidally along orthogonal directions. If the motions of the dots are in phase, we do not perceive this most simple configuration but rather the endpoints of a rod sliding sideways along the $45^{\circ}$ direction and changing length with the same frequency. Johansson (1950) was the first to point out that the perceptual solutions that we adopt spontaneously in

This work was partly supported by Fonds National pour la Recherche Scientifique Research Grant 31.25265.88 (MUCOM Esprit Project).

Roland Schneider recorded the scribbling movements used to estimate the parameters of the random trajectories. Yushi Suzuki helped us with the implementation of the iterative algorithm for the generation of these trajectories. We are grateful to Dennis Proffitt, Sverker Runeson, and an anonymous reviewer for their many helpful suggestions for an earlier version of this article.

Correspondence concerning this article should be addressed to Paolo Viviani, Department of Psychobiology, Faculty of Psychology and Educational Sciences, Université de Genève-24, Rue de Général Dufour CH-1211, Geneva-4, Switzerland. this and other similar situations can be predicted on the basis of consistent rules concerning the velocity vectors of the stimuli. More recently, Restle (1979) presented further evidence that that phenomenal appearance of certain movingdot patterns is dictated by a principled set of decomposition and selection rules originating within the perceptual system itself.

Other results suggest an implicit knowledge about the dynamics of real bodies and consequently an influence of such knowledge on the genesis of visual percepts. For instance, consider the case of a spot moving back and forth along a rectilinear trajectory with constant velocity. As shown by Runeson $(1974,1975)$, most viewers have the impression that the velocity of the dot is distinctly nonuniform in the proximity of the points at which the direction of the movement is inverted. Cohen (1964), Goldstein and Wiener (1963), and Johansson (1950) reported similar effects. Conversely, harmonic motions, whose velocity is highly nonuniform, are accepted by most observers as plausible instances of constantvelocity movements. Runeson (1974) argued that perceptionbased reports about these dynamic stimuli conform with correct descriptions of possible physical events. The influence of dynamic preconceptions need not be limited to the case of very simple moving stimuli. Indeed, recent experiments (Freyd, 1987; Freyd, Pantzer, \& Cheng, 1988) have shown that perceptual memory of both naturalistic images and handwriting is affected in ways that are compatible with such an influence.

Motor theories of perception represent yet another way of qualifying this general view. In their long history, these theories have considered many sensory modalities (vision, touch, and hearing) and have known many versions (cf. Scheerer, 1984, 1987; Viviani, 1990; Viviani \& Stucchi, 1992). Here we concentrate on just one version, namely the one that is based on the assumption that the process of perceptual selection is constrained or guided by motor schemes, that is, by procedural, implicit knowledge that the central nervous system has with regard to the movements it is capable of producing. The idea is not new and can actually be traced back to the intuitions of Mach (1885/1897) and Poincaré (1905/1952). 
More recently, however, it has attracted a renewed interest by cognitive theorists (e.g., Shepard, 1984) and speech scientists (e.g., Liberman \& Mattingly, 1985). More important, the idea has received support from several experimental findings on visual perception.

First, we should mention the exquisite sensitivity of the visual system to certain forms of biological motion. For instance, it is known that gait (Beardworth \& Bukner, 1981; Cutting, 1981; Cutting \& Proffitt, 1981; Johansson, 1973) and other biomechanical patterns such as dancing (Johansson, 1973) can be recognized reliably even when they are described visually in the most succinct way. In addition, the fact that this amazingly fine perceptual tuning already appears to be in place before 5 months of age (Bertenthal, Proffitt, \& Cutting, 1984; Bertenthal, Proffitt, \& Kramer, 1987) strongly points to the existence of unlearned motor schemes that somehow interact with visual perception. It has been suggested (Hoffman \& Flinchbaugh, 1982) that these motor schemes are instrumental for providing a veridical three-dimensional (3D) interpretation of the retinal images. Moreover, further evidence of a motor component in the interpretation of visual information has come from the results of two experiments on visuomanual pursuit tracking (Viviani, Campadelli, \& Mounoud, 1987; Viviani \& Mounoud, 1990), which show that it is virtually impossible to accurately pursue two-dimensional (2D) targets that do not comply with certain regularities that characterize biological motions.

Dynamic visual illusions represent an important source of support for the particular motor theory of perception to which we are adverting because there are many equivalent ways of representing the world faithfully but only few ways of producing specific distortions. Each condition in which our perceptions are systematically at variance with the objective description of the visual stimuli points then to an equally specific peculiarity of our internal representations, which (so goes the theory) are partly responsible for these perceptions. In favorable cases, it may also point to the reason(s) for such a peculiarity. A case in point is the recent study by Shiffrar and Freyd (1990) of the apparent motion generated by rapidly alternating pictures of the human body. It was shown that when shortest-path motion solutions are pitted against solutions compatible with anatomical constraints, and stimulus onset asynchronies are in the range of biological timing, subjects tend to perceive the compatible solution.

The demonstration of motor-perceptual interactions can be particularly cogent if the illusory effect carries the imprint of a specific and peculiar property of the motor system. This is the case of an illusion that we have documented in a previous article (Viviani \& Stucchi, 1989). Before summarizing the results presented there, we go briefly over the motivation and background for that work, which are also directly relevant to the present study.

\section{A Characterization of Biological Movement}

The movement of a point in an $(x, y)$ plane can be thought of as the conjunction of two components: the trajectory $y=$ $f(x)$ that describes its shape and the law of motion $s=s(t)$ that describes the increase in time of the length of the trajec- tory from the starting position. Mathematically, the two components are independent: Knowing the shape, one cannot infer the law of motion and vice versa. This independence almost always vanishes, however, when the movement represents a physical event. For instance, when an unconstrained inertial mass moves according to Newton's dynamic equation, both the trajectory and the law of motion are uniquely defined by the force field. Consequently, they are functionally related. More generally, the same happens whenever the cause of the movement is related to the effects in a predictable, principled manner. Knowing the time course of the agent and the rules that prescribe its effects, one can predict the kinematics of the movement from its trajectory and vice versa. Conversely, any systematic relation between kinematics and trajectory points to the existence of a principled guidance.

Evidence for such systematic relations has been found in the endpoint movements of the upper limbs in humans and in particular in planar drawing movements (Lacquaniti, Terzuolo, \& Viviani, 1983; Viviani \& Schneider, 1991; Viviani \& Terzuolo, 1982). To be sure, arm, forearm, and hands are inertial objects that react to muscular torques according to equations of dynamics. But the presence of internal constraints and the fact that the active muscular torques at the joints are controlled by exceedingly complex and poorly understood nervous processes rules out the possibility of relating the form and the kinematics of these movements solely on the basis of dynamic principles. Nevertheless, it is possible to provide an empirical description of these relations. In particular, it was found that the relation

$$
V(t)=K\left(\frac{R(t)}{1+\alpha R(t)}\right)^{\beta}, \quad \alpha \geq 0, K(t) \geq 0
$$

between the tangential velocity $V(t)$ and the radius of curvature $R(t)$ of the trajectory is satisfied with good approximation by virtually all endpoint movements of the hand-arm system. When $\alpha=0$, Equation 1 can also be written in terms of angular velocity $A$ and curvature $C: A(t)=K C(t)^{1-\beta}$. Because in adults the experimental value of the exponent $\beta$ is very close to $\frac{1}{3}$, the term two-thirds power law has been suggested to refer to the regularity expressed by Equation 1. For consistency, we adopt this term here. The parameter $\alpha$ is 0 when the trajectory of the movement has no points of inflection. Otherwise, its value depends on the average velocity of the movement. Typical values range between 0 and .1 . The parameter $K$ (called the velocity gain factor) is constant over relatively long segments of the trajectory. Its value depends on the general tempo of the movement and on the length of the segment (Viviani \& McCollum, 1983). Changes in $K$ tend to occur either at points of inflections or at the junction between figural units (Lacquaniti, Terzuolo, \& Viviani, 1984; Viviani, 1986; Viviani \& Cenzato, 1985).

Figure 1 illustrates all of these findings in the case of extemporaneous scribbling movements. Briefly, the demonstration is based on the following steps (see also the references quoted earlier). The movement trajectory (Panel A) is divided into segments, the endpoints of which are the points of inflection. A nonlinear fitting technique is then used to estimate the parameter $\alpha$ for the entire movement and the velocity gain factor $K$ for each segment. Panel B shows the 

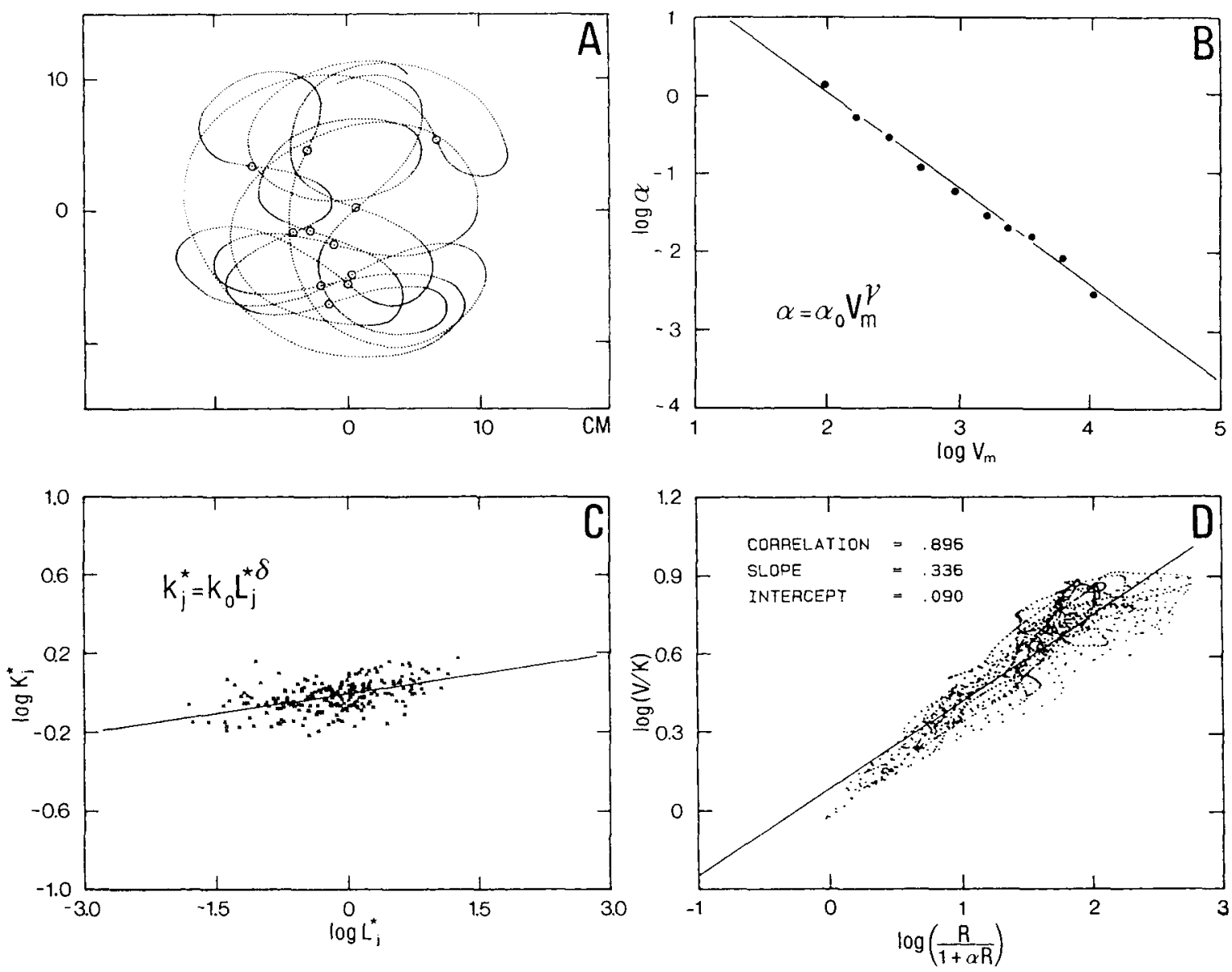

Figure 1. The two-thirds power law for spontaneous drawing movements. (The validity of Equation 1 is demonstrated, and estimation of the parameters is depicted. Typical results are obtained from the analysis of 360 scribbles of 10 different sizes recorded with a digitizing table [sampling rate, $100 \mathrm{~Hz}$; accuracy, $0.025 \mathrm{~mm}$ ] in 12 adult subjects who did not participate in the perceptual experiments [3 repetitions for each size and each subject]. Panel A: Example of a scribble. The trace was divided into successive segments with the points of inflection [circles] as a criterion. Panel B: The parameter $\alpha$ in Equation $I$ is a function of the average velocity. A nonlinear [simplex] algorithm was used to estimate the parameter $\alpha$ independently for each segment of each scribble by fitting Equation 1 to the velocities and radii of curvature of the segments. Estimates of $\alpha$ for each size were averaged and plotted [in log$\log$ scales] as a function of the corresponding average tangential velocity $V_{m}$. An empirical powerfunction fitting to the data points [see inset] adequately describes the inverse relation between $V_{m}$ and $\alpha\left[\alpha_{0}=12.02 ; \sqrt{ }=-1.236\right]$. Notice that the velocity values in this panel refer to actual movements and not to those of the stimuli on the screen. Panel C: Data from a subset of 30 scribbles of the same size as the one shown in Panel A with a scatterplot [in $\log -\log$ scales] of the length $L_{j}^{*}$ of the $j$ th segment [normalized to the average length of all segments] and the average velocity gain factor $K_{j}^{*}$ [normalized to the average for the entire scribble]. The velocity gain factor for each segment depends on the length of the segment. An empirical power-function fitting [see inset] was used to describe quantitatively the relation between gain and length: $K_{0}=-.007 ; \delta=.064$. Panel D: Scatterplot [in log-log scales] of $V[t] / K_{j}$ versus $R[t] /\{1+\alpha R[t]\}$ for the example shown in Panel A. The parameter $\alpha$ for the entire scribble and the velocity gain factors $K_{j}$ for each segment were calculated according to the analytical expressions shown in Panels $B$ and $C$. This typical result demonstrates that Equation 1 accurately represents the covariance between geometry and kinematics that characterizes spontaneous $2 \mathrm{D}$ drawing movements. The expressions in Panels B and C were used in the generation of the visual stimuli; see the Method section of Experiment 1.)

relationship between $\alpha$ and the average velocity. Panel C shows the scatter diagram that obtains by plotting in a doubly logarithmic scale the normalized segment gain versus the normalized segment length. Power-function approximations to the empirical relations shown in Paneis $B$ and $C$ are reported as well. Finally, Panel D demonstrates the validity of Equation 1 in the case of the example shown in Panel A. In effect, a linear relation results when one plots the quantities 
$V(t) / K$ and $[R(t) /(1+\alpha R(t))]$ in logarithmic scales. Notice that the slope of the relation, that is, the least square estimate of the exponent $\beta$, is almost exactly $\frac{1}{3}$. It can be demonstrated (see the Appendix) that if the movement is constrained by Equation 1, the law of motion $s=s(t)$ is completely determined by the shape of the trajectory. In conclusion, a 2D movement that follows a certain trajectory qualifies as a biological movement if and only if the velocity varies along the trajectory in the specific way prescribed by Equation 1 with $\beta=\frac{1}{3}$.

\section{Movement-Related Visual Illusions}

Any movement obtained by vectorially composing two harmonic functions with the same frequency follows an elliptic trajectory and satisfies Equation 1 with $\beta=\frac{1}{3}$. The term Lissajous elliptic movement (LEM) was introduced to refer to this class of dynamic events (Viviani \& Schneider, 1991). The tangential velocity of an LEM oscillates between a maximum attained at the points of minimum curvature and a minimum attained at the points of highest curvature. The ratio of the maximum to the minimum values is a function of the eccentricity $\Sigma: V_{\min } / V_{\max }=\left(1-\Sigma^{2}\right)^{1 / 2}$. Because of what we said earlier, it follows that in drawing ellipses, humans produce laws of motion that are accurately predicted by the LEM model. In particular, circles are always drawn at constant velocity.

Viviani and Stucchi (1989) investigated how we perceive movements in which the law of motion deviates from this "natural" model. A light-point stimulus traced continuously elliptic trajectories. The eccentricity was controlled by the subjects and ranged between $\Sigma=.7-\mathrm{a}$ rather elongated shape-and $\Sigma=0$-a circle. The law of motion instead was invariable and controlled by the experimenter. Three different laws of motions were tested. In one series of trials, the velocity was kept constant (a special case of Equation 1 corresponding to $\beta=0$ ). In a second series, the velocity along the trajectory was modulated as prescribed by Equation 1 for $\beta=\frac{1}{3}, \Sigma=.9$, and a horizontal major axis. In a third series the velocity was again computed by using Equation 1 with $\beta=\frac{1}{3}$ and $\Sigma=.9$, but the major axis was assumed to be vertical. For each condition, subjects were asked to adjust the eccentricity until they perceived a circle. In all three cases, the majority of the subjects made significant errors.

The most salient result, which is directly relevant to the experiments reported here, was that when a circle $(\Sigma=0)$ was traced by a spot that decelerated around the 3 o'clock and 9 o'clock positions as prescribed by a horizontal LEM with $\Sigma$ $=.9$ and $\beta=\frac{1}{3}$, there was a definite tendency to actually perceive a horizontal ellipse. To explain this result, we hypothesized that the structural regularities of our own movements are taken into account in the interpretation of external movements. If so, we reasoned, our experiment induced a conflict between the geometry and the kinematics of the stimuli, which, as attributes of a natural movement, were mutually incompatible. The illusory distortion of the geometry of the stimuli could then be construed as an unconscious attempt by the perceptual system to ally this conflict.
These findings are in keeping with the hypothesis of a motor component in the interpretation of visual information. The hypothesis, however, would become more compelling if we were able to generalize the conclusions of that study to other experimental conditions. The experiments reported here were designed to extend the previous study in two directions. First, we inverted the role of the geometric and kinematic variables with respect to Viviani and Stucchi (1989). There, the velocity was imposed by the experimenter, and the subject could vary the shape of the trajectory to meet a geometrical criterion. Here, the trajectory is invariable, and the subject can adjust the velocity to meet a kinematical criterion. Second, we consider both the case of simple regular shapes, as we did previously, and the more general case of complex unpredictable trajectories.

\section{Experiments 1 and 2}

\section{Method}

\section{Subjects}

Thirteen undergraduate students from the University of Geneva ( 5 men and 8 women) participated in the experiments and were paid for their services. They had normal or corrected-to-normal vision. All subjects but 1 were naive as to the purpose of the experiments.

\section{Apparatus}

The experiments were run in a quiet room kept in very dim light. An Olivetti M290 personal computer was used to present the stimuli and record the answers. Subjects were sitting in front of the display (VGA interface with a resolution of $640 \times 480$ pixels) and freely chose the most comfortable viewing distance (typically between 35 and $45 \mathrm{~cm}$ ). Responses were given through the computer keyboard.

\section{Stimuli}

In Experiment 1 the stimuli were ellipses (E); in Experiment 2 stimuli were pseudorandom closed scribbles (SC). Ellipses were defined by 800 pairs of coordinates, and scribbles were defined by 2,000 pairs. Smooth movements of a light spot $(\phi \approx 0.35 \mathrm{~mm})$ with no appreciable flickering were simulated by displaying sequentially each pair of coordinates on the computer screen. The persistence of the screen and the luminance of the spot were such that no more than 1 $\mathrm{cm}$ of trajectory was visible at all times. The display rate (samples per second [sps]) was kept constant for each experimental condition (207.8 sps for ellipses and 86.9 sps for scribbles). Thus, the duration of a complete cycle of motion was always equal to $3.85 \mathrm{~s}$ for ellipses and 23.00 for scribbles. The apparent instantaneous tangential velocity of the spot was specified uniquely by the spacing between successive samples. Average velocities over one cycle depended on the perimeters of the trajectories and ranged from $9.67 \mathrm{~cm} / \mathrm{s}\left(E_{1}\right)$ to 7.13 $\mathrm{cm} / \mathrm{s}\left(\mathrm{E}_{7}\right)$ for ellipses and from $6.26 \mathrm{~cm} / \mathrm{s}\left(\mathrm{SC}_{4}\right)$ to $6.83 \mathrm{~cm} / \mathrm{s}\left(\mathrm{SC}_{1}\right)$ for scribbles. During a trial, the spot traced out the same trajectory over and over until the subject intervened either to modify the stimulus or to end the trial with a response. Form and kinematics of the stimuli were controlled independently, as specified in the following. 


\section{Geometry}

Ellipses. Seven ellipses were tested $\left(E_{1}-E_{7}\right)$. In all cases, the major axis was rotated by $45^{\circ}$ counterclockwise. The major semiaxis $\left(B_{x}\right)$ had a fixed length on the screen of $6.4 \mathrm{~cm}$ (at a viewing distance of $40 \mathrm{~cm}$, this corresponds to a visual angle of $0.16 \mathrm{rad}$ ). The minor semiaxis $\left(B_{y}\right)$ was instead variable. The semiaxis ratio $B_{y} / B_{x}$ could take the following values: $.85\left(\mathrm{E}_{1}\right), .75\left(\mathrm{E}_{2}\right), .65\left(\mathrm{E}_{3}\right), .55\left(\mathrm{E}_{4}\right), .45\left(\mathrm{E}_{5}\right)$, $.35\left(\mathrm{E}_{6}\right)$, and $.25\left(\mathrm{E}_{7}\right)$. The corresponding values of the eccentricity were $\Sigma=.527, .661, .760, .835, .893, .936$, and .968 . The perimeters ranged from $37.25 \mathrm{~cm}$ for $E_{1}$ to $27.44 \mathrm{~cm}$ for $E_{7}$. Panel $A$ of Figure 2 shows the trajectories of $E_{1}$ and $E_{7}$.

Scribbles. Five pseudorandom closed trajectories were generated with the following procedure. Consider the family of trajectories defined by the following Cartesian parametric equations: $x(\phi)=$ $\sum_{k=1}^{4} A_{x k} \sin \left(2 \pi f_{x k} \phi\right)$ and $y(\phi)=\sum_{k=1}^{4} A_{y k} \sin \left(2 \pi f_{y k} \phi\right)$ (the parameter $\phi$ does not necessarily represent time; see the Appendix). Suppose that one amplitude for each Cartesian component (say, $A_{x 4}$ and $A_{y 4}$ ) is fixed. Suppose further that we fix four nonoverlapping intervals $I_{k}=$ $[c k, c(k+1)](k=1,4 ; c \geq 0]$, and in each of them we choose at random two frequency values, $f_{x k}$ and $f_{y k}$. To any choice of the frequencies is associated a set of trajectories (one for each set of amplitudes $A_{x k}$ and $A_{y k}, k=1,3$ ), most of which will be open. For a trajectory to be closed, there must be a value $T$ of $\phi$ such that $x(0)=$ $x(T)$ and $y(0)=x(T)$. If one also imposes a continuity constraint on the tangent and on the curvature of the trajectory at $\phi=T$, it must be that $x(0)=x(T), d x(\phi) /\left.d \phi\right|_{\phi=0}=d x(\phi) /\left.d \phi\right|_{\phi=T}, d^{2} x(\phi) /\left.d \phi^{2}\right|_{\phi=0}$ $=d^{2} x(\phi) /\left.d \phi^{2}\right|_{\phi=T}, y(0)=y(T), d y(\phi) /\left.d \phi\right|_{\phi=0}=d y(\phi) /\left.d \phi\right|_{\phi=0}=$ $d y(\phi) /\left.d \phi\right|_{\phi=T}$, and $d^{2} y(\phi) /\left.d \phi^{2}\right|_{\phi=0}=d^{2} y(\phi) /\left.d \phi^{2}\right|_{\phi=T}$. These six conditions translate into two systems of three independent linear equations. Each system involves only three unknowns, that is, the unspecified amplitudes $A_{x k}$ and $A_{y k}(k=1,3)$. Solving the two systems yields the unique continuous closed trajectory that corresponds to the fixed value of $T$ and to the randomly selected frequencies. An infinite number of pseudorandom scribbles can be generated with this scheme. Although the shapes of the scribbles are different, they all share the set of values that are assumed to be fixed, namely the amplitudes $A_{x 4}$ and $A_{14}$, the total period $T$, and the constant $c$. The amplitudes determine the overall size of the trajectories. The second $(T)$ and the third $(c)$ parameters jointly determine their average length. For reasons that become apparent later, we imposed the further constraint that the curvature of the trajectories (on the screen) should never exceed $2.5 \mathrm{~cm}^{-1}$. Moreover, we also wanted to limit the dispersion of the trajectories around their center of gravity. This can be obtained by imposing additional constraints on the spread of amplitudes values: $\left[\left(-.9 A_{x 4} \leq A_{x k} \leq-.5 A_{x 4}\right)\right.$ or $\left.\left(.5 A_{x 4} \leq A_{x k} \leq .9 A_{x 4}\right)\right]$ $(k=1,3),\left[\left(-.9 A_{y 4} \leq A_{y k} \leq-.5 A_{y 4}\right)\right.$ or $\left.\left(.5 A_{y 4} \leq A_{y k} \leq .9 A_{y 4}\right)\right](k=1$, 3). A Monte Carlo program was used to generate 100 trajectories corresponding to the following parameter values and satisfying all required constraints: $A_{x 4}=7.0, A_{y 4}=5.0, T=10$, and $c=.542$. Then, we searched these 100 acceptable solutions for five scribbles $\left(\mathrm{SC}_{1}\right.$ to $\left.\mathrm{SC}_{5}\right)$ that had $2,4,6,8$, and 10 points of inflections, respectively, the perimeters of which were closest to each other. These perimeters (in $\mathrm{cm})$ were $157.02\left(\mathrm{SC}_{1}\right), 150.22\left(\mathrm{SC}_{2}\right), 145.10\left(\mathrm{SC}_{3}\right)$, $144.04\left(\mathrm{SC}_{4}\right)$, and $150.40\left(\mathrm{SC}_{5}\right)$. Panel $\mathrm{B}$ of Figure 2 shows the trajectory of $\mathrm{SC}_{3}$.

In an ellipse, the curvature varies continuously between $C_{\min }=B_{y} /$ $B_{x}^{2}$ and $C_{\max }=B_{x} / B_{y}^{2}$. The largest variation occurred for $\mathrm{E}_{7}$, where $C_{\min }=0.039 \mathrm{~cm}^{-1}$ and $C_{\max }=2.5 \mathrm{~cm}^{-1}$. In pseudorandom trajectories, curvature ranged from 0 (points of inflection) to a value very close to the preset limit of $2.5 \mathrm{~cm}^{-1}$. Panel A of Figure 3 shows the distribution functions of the curvature for all ellipses. Panel $\mathrm{B}$ of the same figure shows the distribution for $\mathrm{SC}_{3}$ and $\mathrm{SC}_{5}$.

\section{Kinematics}

In both experiments the tangential velocity of the stimulus, $V(t)$, was related to the radius of curvature, $R(t)$, of the trajectory through the following generalization of Equation 1 :

$$
V(t)=K(t)\left(\frac{R(t)}{1+\alpha R(t)}\right)^{\beta}, \quad \alpha \geq 0, K(t) \geq 0,
$$

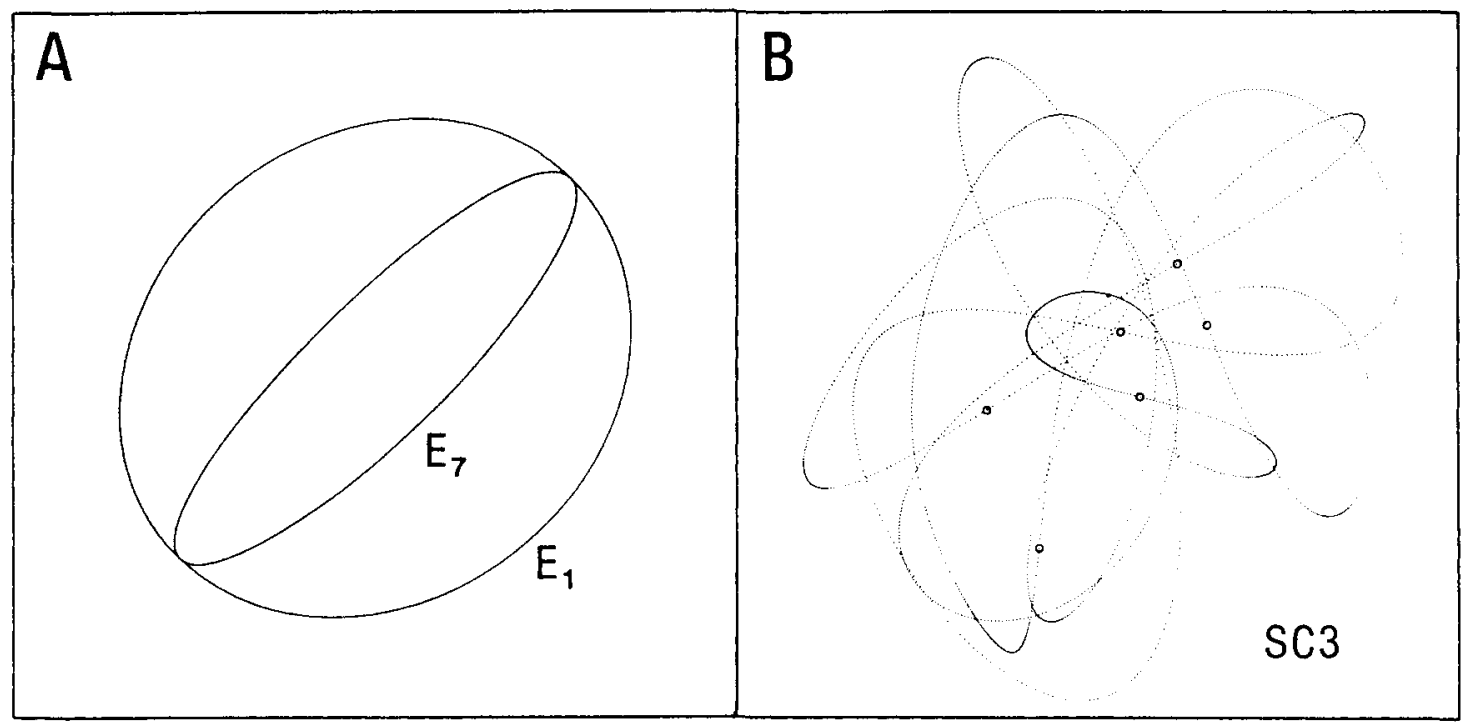

Figure 2. Representative examples of the trajectory of the stimuli. (Panel $A$ : The least $\left[\mathrm{E}_{1}\right]$ and most $\left[\mathrm{E}_{7}\right]$ eccentric ellipse [superimposed]. Notice that ellipses were not isoperimetric. Movement was counterclockwise direction. Panel B: One of the five pseudorandom closed trajectories $\left[\mathrm{SC}_{3}\right]$. Circles identify the points of inflection that separate successive segments. They where not visible in the actual display.) 


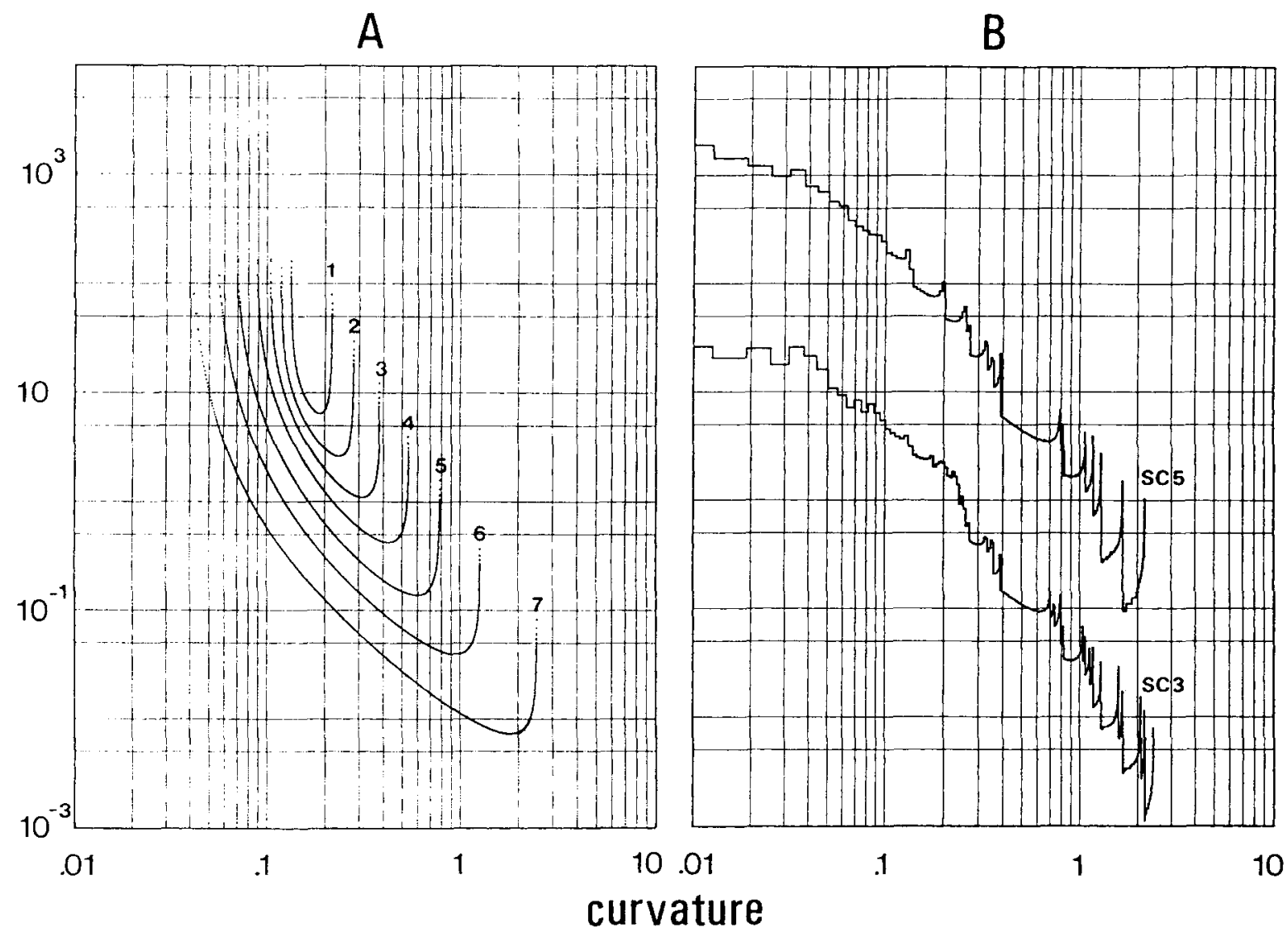

Figure 3. Probability density distribution of the curvature of the stimuli (log-log scales). (Panel A: distributions for all ellipses calculated analytically. Panel B: Distributions for two scribbles $\left[\mathrm{SC}_{3}\right.$ and $\mathrm{SC}_{s}$ ] each estimated on the basis of $1,500,000$ equispaced samples. The coordinates of the samples were computed through Equation A 10 [see the Appendix]. For clarity, the distribution for $\mathrm{SC}_{3}$ has been shifted upward by two log units. Notice that scribble distributions result from the superposition of several components, each similar to the ellipse distributions. The figure demonstrates that the range of curvature values in the scribbles exceeds the range for ellipses. The smaller the eccentricity, the larger the range difference.)

where $K(t)$ (velocity gain factor) is a known function, and $R(t)$ is uniquely specified by the form of the trajectory. Voluntary movements in adults satisfy this power law with $\beta=\frac{1}{3}$ and $K(t)$ piecewise constant (see the introduction). Thus, the relation between kinematics and geometry realized in the visual stimuli represents the generalization of an empirical relation that is satisfied in actual movements. When $\beta>0$ the instantaneous tangential velocity decreases with the curvature. When $\beta<0$ the opposite occurs. Finally, when $\beta=0$ the tangential velocity is independent of the curvature and is equal to $K(t)$. The Appendix describes the procedure for choosing the spacings between trajectory samples so that Equation 2 is satisfied by the movement of the light spot.

Ellipses. For these trajectories (which have no inflections), we set $\alpha=0$ and $K(t)=K=$ constant. Twelve values of $\beta$, equally spaced (step $\left.=\frac{1}{11}\right)$ in the interval $[-.250, .666]$, were tested. In continuous time, once the semiaxes and the parameters $\alpha$ and $\beta$ are fixed, the instantaneous velocity (and therefore the period $T$ ) of a motion satisfying Equation 2 is uniquely determined by the velocity gain factor $K$ (see the Appendix). Numerically, however, the choice of $K$ is not constrained. Thus, for all ellipses we set the arbitrary value $K$ $=20$, and we computed the (constant) time interval between samples to complete one cycle in exactly 800 samples (see Equation A10). Panel A of Figure 4 illustrates the modulation of the tangential velocity across a complete cycle of $E_{5}$ for some selected values of the exponent $\beta$. Notice that because $K(t)=$ constant, the tangential velocity is constant when $\beta=0$.

Scribbles. For all five pseudorandom stimuli, we set the parameter $\alpha$ according to the empirical power law described in Panel B of Figure 1. The values of $\alpha$ ranged from .09 to .1. The time-varying velocity gain factor $K(t)$ was defined with a three-step procedure. First, we measured for each scribble the linear extent, $L_{j}$, of the segments of trajectory between successive points of inflections. Then, for each segment, we computed a constant gain, $K_{j}$, according to the power law $K_{j}=K_{0} L_{j}^{\delta}$, where the exponent $\delta$ was estimated as described in Panel $\mathrm{C}$ of Figure 1. Finally, the function $K(t)$ was obtained by replacing the step jumps between successive values $K_{j}$ with smooth transitions (splining with segments of logistic functions). For any value of $\alpha, \beta$, and $\delta$, the duration $T$ of one complete cycle of the motion depends only on the parameter $K_{0}$. Unlike the case of the ellipse, the fact that the gain is variable bars the possibility of choosing $K_{0}$ arbitrarily. The value of $K_{0}$ required to obtain the desired period of $23.00 \mathrm{~s}$ (i.e., one cycle in 2,000 samples) was determined in each case (i.e., for each scribble and each $\beta$ ) with a method of successive approximations. Twelve values of $\beta$, equally spaced (step $=\frac{1}{12}$ ) in the interval $[-.166,7.50]$, were tested. Panel $B$ of Figure 4 illustrates the modulation of the tangential velocity across a complete cycle of $\mathrm{SC}_{2}$ 


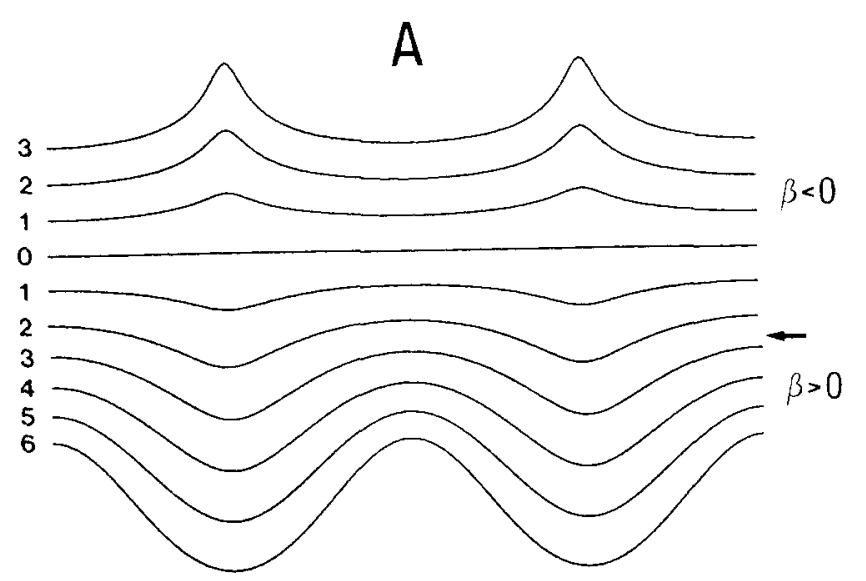

B

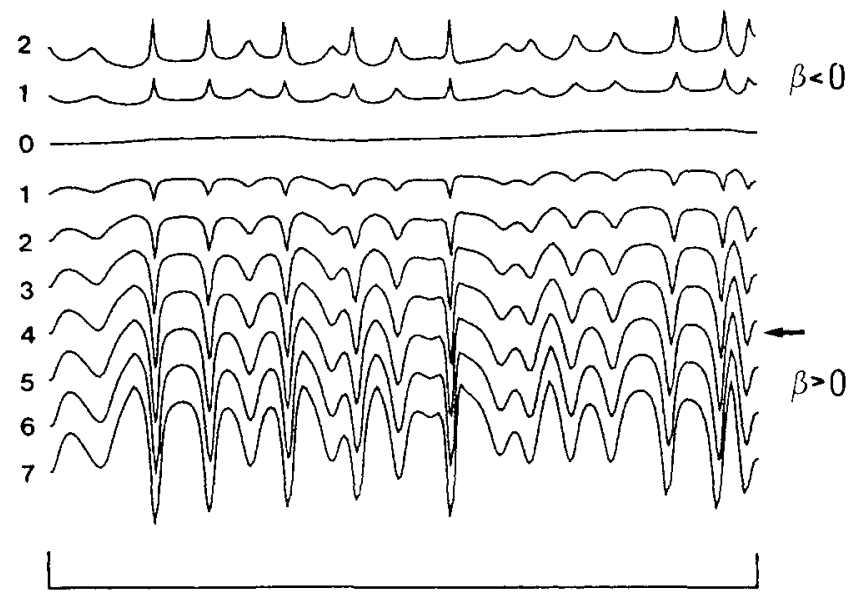

Figure 4. Profiles of tangential velocity. (Panel A: Ellipse $E_{5}[\Sigma=$ .893 , the curvature-dependent modulation of velocity decreases at an equal rate with the eccentricity]. Panel $\mathrm{B}$ : Scribble $\mathrm{SC}_{2}$. Each curve is relative to the selected values of $\beta$ [indicated as multiples of the step ratio, $\frac{1}{12}$ ]. In both panels, vertical scales are identical, and zero references are displaced vertically by an amount proportional to the corresponding $\beta$ values. Horizontal scales are normalized to one complete cycle of movement. When $\beta<0$, maxima of velocity occur when curvature is maximum. Maxima turn into minima when $\beta>$ 0 . When $\beta=0$, velocity is constant in ellipses and only slightly varying in scribbles. For $\beta=\frac{1}{3}$, the ratio between maximum and minimum velocity is $B_{x} / B_{y}=2.22$ in $\mathrm{E}_{5}$ and 2.61 for $\mathrm{SC}_{2}$. Arrows indicate the position on the $\beta$ scale of the average value that produced a subjectively constant velocity; see Figures 6 and 8.)

for some selected values of the exponent $\beta$. Notice that unlike the case of the ellipses, the velocity is never constant, even when $\beta=0$. The residual modulations, however, derive entirely from those of the velocity gain factor $K(t)$ and are quite modest.

\section{Task and Experimental Procedure}

All subjects participated in both experiments. An experiment was run in a single session with two short periods of rest. Some subjects were tested with ellipses first and then, on a different day, with scribbles. Others were tested in the reverse order. Task and experimental procedure were identical in the two cases. The task was to choose for any given shape the law of motion that resulted in the least absolute variation of velocity along the trajectory. Because variations could be exactly zero only in the case of ellipses, in phrasing the task we used the notion of most uniform velocity. Subjects were told that the task always had a unique correct solution. In Experiment 1 they were also told explicitly that moving targets followed elliptic trajectories with different eccentricities (the number of possible eccentricity values was left unspecified). Instead, in Experiment 2 scribbles were simply described as irregular and unpredictable trajectories. We did not specify that scribbles too were closed (albeit complex) trajectories and that only five of them were actually being displayed. After an informal verbal introduction, a computer-aided familiarization phase began in which written explanations alternated with warm-up examples. Subjects then started the session by pressing a key that caused the immediate appearance of a moving spot on the computer screen. They could view the display for as long as they wished, trying to decide whether the velocity of the spot was the most uniform. If they did not think that that was the case, they could modify the kinematics of the movement by pressing either the $[<]$ or the $[>]$ key. The action of these keys was described as complementary. The first would increase the velocity in the more curved portions of the trajectory and reduce by a comparable amount the velocity in the flatter regions. The other would have the opposite effect. In reality, pressing these two keys decreased or increased by one step the value of the exponent $\beta$, respectively. No change occurred if the subject attempted to increase the value of $\beta$ beyond 1 or decrease it below -1 . Immediately after a keypress, the spot disappeared for about 500 $\mathrm{ms}$ and then appeared again in the position that it would have reached if it had continued with the previous law of motion. The motion then continued along the same trajectory but with different kinematics. No limit was set to the number of changes the subject could try before reaching a decision. Actually, in the warm-up phase subjects were encouraged to explore the available possibilities leisurely. When the subject was satisfied that he or she had identified the most uniform movement, the trial was terminated by pressing the space bar. The complete history of the trial, including the final selected value of $\beta$, was stored, and another trial began after a $500-\mathrm{ms}$ interval. Experiment 1 comprised 7 (eccentricities) $\times 12$ (initial $\beta$ values) $=84$ trials. Experiment 2 comprised 5 (scribbles) $\times 12$ (initial $\beta$ values) $=60$ trials. Different random permutations of all possible pairings between initial $\beta$ value and type of trajectory were used in each experiment. The selection of the pair was constrained by the rule that successive initial values of $\beta$ differed by more than three steps.

\section{Results and Discussion}

Even though the formulation of the response criterion was somewhat vague (see the Method section), all subjects reported that the task was both clearly defined and quite easy. Only 1 subject consistently went through more than 20 steps before reaching a decision. Questioned after the experiments, the subjects unanimously indicated that the stimuli were perceived as $2 \mathrm{D}$ and that no conscious feeling of depth was elicited.

\section{Ellipses}

Every subject made large errors in indicating the most uniform velocity profile. Figure 5 illustrates the results for 1 representative subject. Panels A-G show the complete se- 

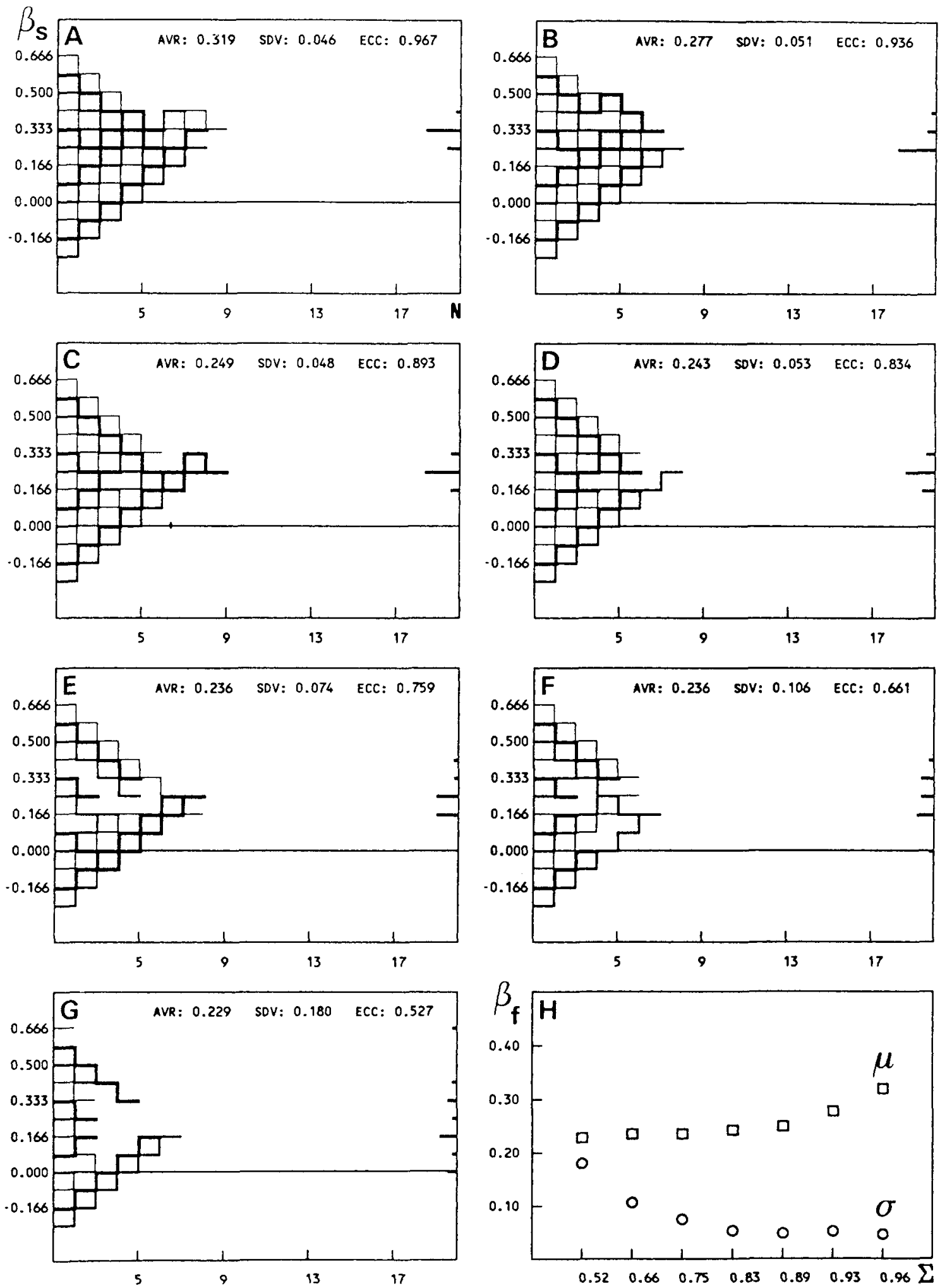

Figure 5. Subjective estimation of uniform velocity: Elliptic movements. (Results for a typical subject. Staircase plots in Panels A-G [one for each indicated eccentricity] describe the 12 sequences of $\beta$ values [ 1 for each starting value $\beta_{s}$ ] tested by the subject before reaching a decision. Thicker lines indicate overlap of two or more sequences. The right of each panel shows the histograms of the final estimates. Panel $\mathrm{H}$ depicts the averages [squares] and standard deviations [circles] of $\beta_{f}$. For clarity, data points are scaled horizontally according to the value of the semiaxis ratio corresponding to the indicated eccentricity.) 
Table 1

Influence for Ellipses of the Initial Value of the Exponent $\left(\beta_{s}\right)$ on the Number of Steps to Reach a Decision $(N)$ and on the Final Value $\left(\beta_{t}\right)$ : Averages and Standard Deviations Calculated Over All Subjects and Eccentricities

\begin{tabular}{ccccccccccccccc}
\hline \multirow{2}{*}{$\begin{array}{c}\text { Steps/final } \\
\text { value }\end{array}$} & \multicolumn{10}{c}{$\beta_{\text {s values }}$} \\
\cline { 2 - 12 } & -.250 & -.166 & -.083 & .000 & .083 & .166 & .250 & .333 & .416 & .500 & .583 & .666 \\
\hline$N$ & 7.68 & 6.89 & 6.03 & 5.71 & 4.60 & 4.36 & 4.55 & 5.34 & 5.43 & 6.64 & 7.38 & 8.03 \\
$S D$ & 3.61 & 3.80 & 3.61 & 4.16 & 3.28 & 3.11 & 3.90 & 4.49 & 2.48 & 3.86 & 2.99 & 3.41 \\
& & & & & & & & & & & & \\
$\beta_{f}$ & .126 & .114 & .141 & .155 & .158 & .175 & .190 & .202 & .221 & .227 & .232 & .237 \\
$S D$ & .127 & .126 & .104 & .112 & .085 & .073 & .096 & .109 & .104 & .106 & .108 & .138 \\
\hline
\end{tabular}

quence of steps leading to a response for each starting value $\beta_{s}$ and each indicated value of the eccentricity $\Sigma$. The right margins of the frames show the histograms of the final settings $\beta_{f}$. In Panel $\mathrm{H}$, the results for this subject are summarized by plotting the averages (squares) and the standard deviations (circles) of $\beta_{f}$ as a function of eccentricity. The final setting of the exponent depended somewhat on the starting value $\beta_{s}$. This is demonstrated in Table 1 by collapsing over subjects and eccentricities the number of steps to reach a decision $(N)$ and the final $\beta$ values. Clearly, $\beta_{f}$ tended to be higher than the mean when starting from high values of $\beta$, and conversely. In addition, the number of steps as a function of $\beta_{s}$ was $U$ shaped, with a minimum at $\beta_{s} \approx \beta_{f}$. An analysis of variance of $\beta_{f}$ with a 12 (starting values: $\beta_{s}$ ) $\times 7$ (eccentricities: $\Sigma$ ) factorial design and 13 completely repeated measurements per cell $(S)$ revealed significant effects of both variables: $\beta_{s}$, $F(11,132)=14.64, p<.001 ; \Sigma, F(6,72)=6.39, p<.001$. The two-way $\beta_{s} \times \Sigma$ interaction was significant, $F(66,792)=$ $4.46, p<.001$. Individual differences and the effects of the eccentricity are better illustrated by removing the paradigminduced effects of $\beta_{s}$. For each subject and each eccentricity, Table 2 reports the averages and standard deviations of $\beta_{f}$, computed by collapsing the results over $\beta_{s}$.

Figure 6 illustrates in three different forms the pattern of results common to all subjects. Panel A shows for each eccentricity the cumulative probability distribution of $\beta_{f}$ on the basis of $12\left(\beta_{s}\right) \times 13$ (subjects) $=156$ estimates. The shape of all of the distributions is approximately ogival, but the variance increases in going from higher to lower values of $\Sigma$. This variance results from both within-subject variability and the variability among individual averages. The following procedure was used to eliminate the latter contribution (Figure 6 , Panel B). First, we recomputed the cumulative probability distribution after subtracting the individual averages from each $\beta_{f}$ value. Cumulative probabilities were then transformed in $z$ scores (data points that correspond to $\beta$ values for which the probability is either 0 or 1 are missing because the $z$ transform cannot be applied). Finally, the abscissas of the $z$ plots for each eccentricity were displaced by an amount equal to the mean of the individual averages for that eccentricity. A cross indicates the position on the $\beta$ scale of this mean, which represents the constant error (CE) subjects made in estimating constancy of velocity. For comparison, the vertical line indicates the position that corresponds to true constant velocity $(\beta=0)$. With one exception $(\Sigma=.936), z$ scores are well interpolated by linear functions of $\beta$, which confirms that the underlying distributions are approximately Gaussian. The $z$ score plots can be used to compute for each eccentricity the mean just noticeable difference (JND) over all subjects. As customary, we estimated JNDs by the inverse of the slope of the $z$ plot at $z=0$. The results were the following: $.207\left(E_{1}\right)$, $.115\left(\mathrm{E}_{2}\right), .091\left(\mathrm{E}_{3}\right), .071\left(\mathrm{E}_{4}\right), .062\left(\mathrm{E}_{5}\right), .062\left(\mathrm{E}_{6}\right)$, and .054 $\left(E_{7}\right)$. Finally, means over subjects of individual averages of $\beta_{f}$ are plotted in Panel $C$ of Figure 6 as a function of eccentricity. Between-subjects variability of averages is indicated by the $95 \%$ confidence intervals of the mean. The results indicate that both the size of the errors and their consistency increase with eccentricity.

\section{Scribbles}

The results with unpredictable targets confirmed those obtained with predictable ones. Figure 7 illustrates, with the same format of Figure 5, the results of another subject in Experiment 2. Panels A-E show the sequence of steps leading to a response (one panel for each of the five selected scribbles). Panel $F$ shows means and standard deviations of the final setting $\beta_{f}$ (the code number of the scribble in ordinates). The effect of $\beta_{s}$ on both the number of steps $N$ and the final setting $\beta_{f}$ (Table 3 ) is virtually identical to that already documented for ellipses (Table 1). An analysis of variance of $\beta_{f}$ with a 12 starting values $\left(\beta_{s}\right) \times 5$ scribbles $(\mathrm{SC})$ factorial design and 13 completely repeated measurements per cell $(S)$ showed significant effects of both variables: $\beta_{s}, F(11,132)=10.32, p<$ $.001 ; \mathrm{SC}, F(4,48)=9.21, p<.001$. The two-way $\beta_{s} \times \mathrm{SC}$ interaction was also significant, $F(44,528)=1.54, p=.017$. By pooling over the 12 values of $\beta_{s}$, one obtains the averages and standard deviations of $\beta_{f}$ for each subject and each scribble (Table 4). Notice that unlike the case of ellipses, the averages are significantly different from zero ( $p<.01$, one-tailed) for all combinations of these two variables. Finally, Figure 8 summarizes the results obtained in all subjects by using the same procedure and the same conventions as Figure 6 (the only difference is that in Panel C of Figure 8 the independent variables are nominal). The estimated JNDs for each scribble were $.104\left(\mathrm{SC}_{1}\right), .118\left(\mathrm{SC}_{2}\right), .101\left(\mathrm{SC}_{3}\right), .113\left(\mathrm{SC}_{4}\right)$, and .083 $\left(\mathrm{SC}_{5}\right)$. The slight differences of CEs and JNDs among scribbles did not significantly correlate with the number of inflection points. 
Table 2

$B_{f}$ Values for Each Eccentricity and Each Subject: Means and Standard Deviations Calculated Over 12 Values (1 for Each Starting Value $\beta_{s}$ )

\begin{tabular}{|c|c|c|c|c|c|c|c|}
\hline \multirow[b]{2}{*}{ Subject } & \multicolumn{7}{|c|}{ Eccentricity } \\
\hline & $\begin{array}{c}.527 \\
\left(B_{y} / B_{x}=.850\right)\end{array}$ & $\begin{array}{c}.661 \\
\left(B_{y} / B_{x}=.750\right)\end{array}$ & $\begin{array}{c}.760 \\
\left(B_{y} / B_{x}=.650\right)\end{array}$ & $\begin{array}{c}.835 \\
\left(B_{y} / B_{x}=.550\right)\end{array}$ & $\begin{array}{c}.893 \\
\left(B_{y} / B_{x}=.450\right)\end{array}$ & $\begin{array}{c}.936 \\
\left(B_{y} / B_{x}=.350\right)\end{array}$ & $\begin{array}{c}.968 \\
\left(B_{y} / B_{x}=.250\right)\end{array}$ \\
\hline $\begin{array}{l}\mathrm{S}_{1} \\
S D\end{array}$ & $\begin{array}{l}.090 \\
.242\end{array}$ & $\begin{array}{l}.076 \\
.150\end{array}$ & $\begin{array}{l}.076 \\
.110\end{array}$ & $\begin{array}{l}.125 \\
.087\end{array}$ & $\begin{array}{l}.139 \\
.039\end{array}$ & $\begin{array}{l}.139 \\
.062\end{array}$ & $\begin{array}{l}.167 \\
.059\end{array}$ \\
\hline $\begin{array}{l}\mathrm{S}_{2} \\
S D\end{array}$ & $\begin{array}{l}.201 \\
.146\end{array}$ & $\begin{array}{l}.208 \\
.099\end{array}$ & $\begin{array}{l}.201 \\
.063\end{array}$ & $\begin{array}{l}.160 \\
.099\end{array}$ & $\begin{array}{l}.146 \\
.084\end{array}$ & $\begin{array}{l}.174 \\
.099\end{array}$ & $\begin{array}{l}.181 \\
.046\end{array}$ \\
\hline $\begin{array}{l}\mathrm{S}_{3} \\
S D\end{array}$ & $\begin{array}{l}.111 \\
.124\end{array}$ & $\begin{array}{l}.111 \\
.079\end{array}$ & $\begin{array}{l}.090 \\
.063\end{array}$ & $\begin{array}{l}.104 \\
.069\end{array}$ & $\begin{array}{l}.076 \\
.063\end{array}$ & $\begin{array}{l}.153 \\
.031\end{array}$ & $\begin{array}{l}.160 \\
.041\end{array}$ \\
\hline $\begin{array}{l}\mathrm{S}_{4} \\
S D\end{array}$ & $\begin{array}{l}.153 \\
.169\end{array}$ & $\begin{array}{l}.188 \\
.060\end{array}$ & $\begin{array}{l}.194 \\
.071\end{array}$ & $\begin{array}{l}.201 \\
.041\end{array}$ & $\begin{array}{l}.229 \\
.036\end{array}$ & $\begin{array}{l}.229 \\
.036\end{array}$ & $\begin{array}{l}.250 \\
.059\end{array}$ \\
\hline $\begin{array}{l}\mathrm{S}_{\mathrm{S}} \\
S D\end{array}$ & $\begin{array}{l}.118 \\
.134\end{array}$ & $\begin{array}{l}.139 \\
.092\end{array}$ & $\begin{array}{l}.160 \\
.093\end{array}$ & $\begin{array}{l}.160 \\
.063\end{array}$ & $\begin{array}{l}.201 \\
.063\end{array}$ & $\begin{array}{l}.215 \\
.053\end{array}$ & $\begin{array}{l}.236 \\
.031\end{array}$ \\
\hline $\begin{array}{l}\mathrm{S}_{6} \\
S D\end{array}$ & $\begin{array}{l}.174 \\
.277\end{array}$ & $\begin{array}{l}.194 \\
.098\end{array}$ & $\begin{array}{l}.201 \\
.086\end{array}$ & $\begin{array}{l}.181 \\
.031\end{array}$ & $\begin{array}{l}.187 \\
.060\end{array}$ & $\begin{array}{l}.194 \\
.039\end{array}$ & $\begin{array}{l}.222 \\
.052\end{array}$ \\
\hline $\begin{array}{l}\mathrm{S}_{7} \\
S D\end{array}$ & $\begin{array}{l}.194 \\
.211\end{array}$ & $\begin{array}{l}.208 \\
.150\end{array}$ & $\begin{array}{l}.181 \\
.095\end{array}$ & $\begin{array}{l}.236 \\
.057\end{array}$ & $\begin{array}{l}.181 \\
.057\end{array}$ & $\begin{array}{l}.139 \\
.124\end{array}$ & $\begin{array}{l}.201 \\
.041\end{array}$ \\
\hline $\begin{array}{l}\mathrm{S}_{8} \\
S D\end{array}$ & $\begin{array}{l}.278 \\
.283\end{array}$ & $\begin{array}{l}.319 \\
.189\end{array}$ & $\begin{array}{l}.313 \\
.141\end{array}$ & $\begin{array}{l}.264 \\
.095\end{array}$ & $\begin{array}{l}.250 \\
.090\end{array}$ & $\begin{array}{l}.306 \\
.079\end{array}$ & $\begin{array}{l}.326 \\
.063\end{array}$ \\
\hline $\begin{array}{l}\mathrm{S}_{9} \\
S D\end{array}$ & $\begin{array}{l}.132 \\
.154\end{array}$ & $\begin{array}{l}.139 \\
.052\end{array}$ & $\begin{array}{l}.132 \\
.053\end{array}$ & $\begin{array}{l}.125 \\
.042\end{array}$ & $\begin{array}{l}.146 \\
.050\end{array}$ & $\begin{array}{l}.174 \\
.041\end{array}$ & $\begin{array}{l}.167 \\
.000\end{array}$ \\
\hline $\begin{array}{l}\mathrm{S}_{10} \\
S D\end{array}$ & $\begin{array}{l}.229 \\
.180\end{array}$ & $\begin{array}{l}.236 \\
.107\end{array}$ & $\begin{array}{l}.236 \\
.075\end{array}$ & $\begin{array}{l}.243 \\
.053\end{array}$ & $\begin{array}{l}.250 \\
.048\end{array}$ & $\begin{array}{l}.278 \\
.052\end{array}$ & $\begin{array}{l}.319 \\
.046\end{array}$ \\
\hline $\begin{array}{l}\mathrm{S}_{11} \\
S D\end{array}$ & $\begin{array}{l}.236 \\
.169\end{array}$ & $\begin{array}{l}.146 \\
.123\end{array}$ & $\begin{array}{l}.181 \\
.067\end{array}$ & $\begin{array}{l}.174 \\
.105\end{array}$ & $\begin{array}{l}.174 \\
.053\end{array}$ & $\begin{array}{l}.201 \\
.041\end{array}$ & $\begin{array}{l}.174 \\
.053\end{array}$ \\
\hline $\begin{array}{l}S_{12} \\
S D\end{array}$ & $\begin{array}{l}.139 \\
.137\end{array}$ & $\begin{array}{l}.139 \\
.098\end{array}$ & $\begin{array}{l}.132 \\
.079\end{array}$ & $\begin{array}{l}.097 \\
.057\end{array}$ & $\begin{array}{l}.125 \\
.042\end{array}$ & $\begin{array}{l}.167 \\
.034\end{array}$ & $\begin{array}{l}.174 \\
.023\end{array}$ \\
\hline $\begin{array}{l}\mathrm{S}_{13} \\
S D\end{array}$ & $\begin{array}{l}.153 \\
.192\end{array}$ & $\begin{array}{l}.104 \\
.128\end{array}$ & $\begin{array}{l}.167 \\
.068\end{array}$ & $\begin{array}{l}.139 \\
.071\end{array}$ & $\begin{array}{l}.160 \\
.041\end{array}$ & $\begin{array}{l}.181 \\
.031\end{array}$ & $\begin{array}{l}.243 \\
.023\end{array}$ \\
\hline
\end{tabular}

Note. $\quad B_{y} / B_{x}$ denotes the semiaxis ratio of the ellipse.

Experiments 1 and 2 were designed to support the hypothesis that perception of $2 \mathrm{D}$ movements is influenced by an implicit knowledge of the properties of our own movements. All of the stimuli in both experiments satisfied a general relational constraint present in endpoint motion of drawing movements. By varying only one parameter in the formal definition of the constraint-the exponent $\beta$-a controlled mismatch was introduced between the kinematics of the stimuli and that of real voluntary movements. Subjects were asked to adjust this parameter to minimize the variation in tangential velocity along the trajectory. This required setting the exponent to 0 , whereas in real movements $\beta \approx \frac{1}{3}$. Experiment 1 demonstrated that the movement perceived by all subjects as having uniform velocity is actually closer to a Lissajous movement $\left(\beta=\frac{1}{3}\right)$ than to a constant-velocity movement $(\beta=0)$. Experiment 2 extended the validity of this result to the case of complex and unpredictable trajectories. The departure from veridical perception was considerable
(Figure 4) and was present in all 13 subjects, which suggests the involvement of some basic mechanisms of perception.

Before retaining the hypothesis of a motor component in the visual perception of dynamic events, however, we must consider alternative explanations of the observed effects. Specifically, we consider two possibilities. First, subjects implicitly adopted a perceptual definition of most uniform velocity that was at variance with the physical definition. Second, despite the overwhelming flatness cues, perceptual judgments were based unconsciously on a 3D interpretation. Four control experiments were designed to rule out these two possibilities.

\section{Experiment 3}

We tested the hypothesis that the concept of uniform velocity elicited by verbal instructions was not associated with the perceptual correlate of a true constant velocity but rather with the perceptual correlate of a velocity that covaries with 

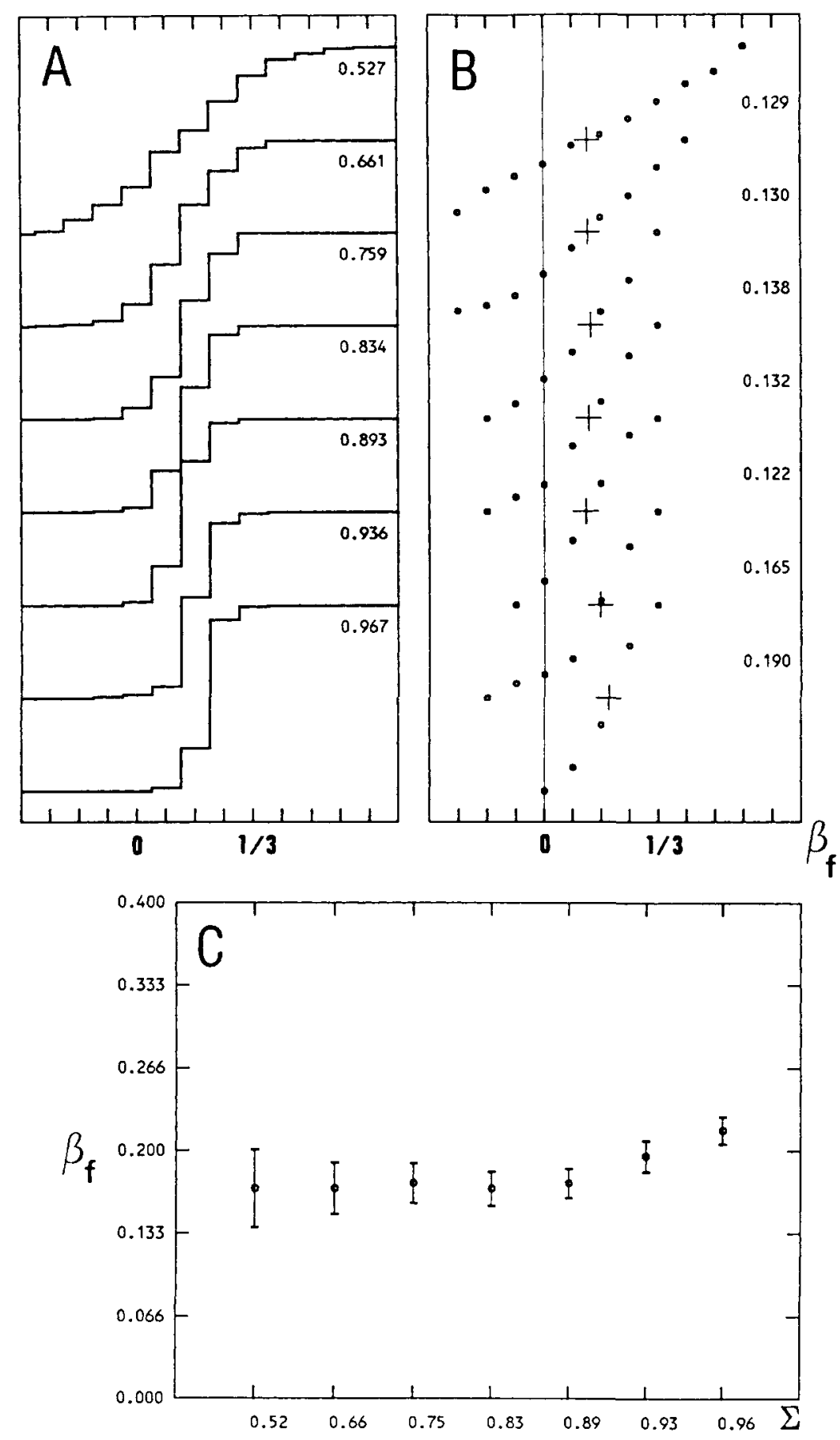

Figure 6. Subjective estimation of uniform velocity: Elliptic movements. (Results for all subjects. Panel A: Cumulative distribution functions of $\beta_{f}$ for the indicated eccentricities [arbitrarily shifted along the vertical axis]. Panel B: $z$ scores for the same data shown in Panel A. Before applying the $z$ transformation to the pooled data, the average of individual distributions has been subtracted from the corresponding values of $\beta_{f} . z$ plots have then been shifted horizontally by an amount equal to the mean of the individual averages. Crosses identify the median of the distributions [numerical values are on the right]. Panel C: Means over subjects of individual averages of $\beta_{f}$ as a function of the eccentricity [scaled linearly as in Figure 5]. Bars indicate the $95 \%$ confidence intervals for the means. Numerical values of the means are as follows: $E_{1}, .170 ; E_{2}, .170 ; E_{3}, .174 ; E_{4}, .170 ; E_{5}, .174 ; E_{6}, .196 ; E_{7}, .217$; overall average, .182.) 

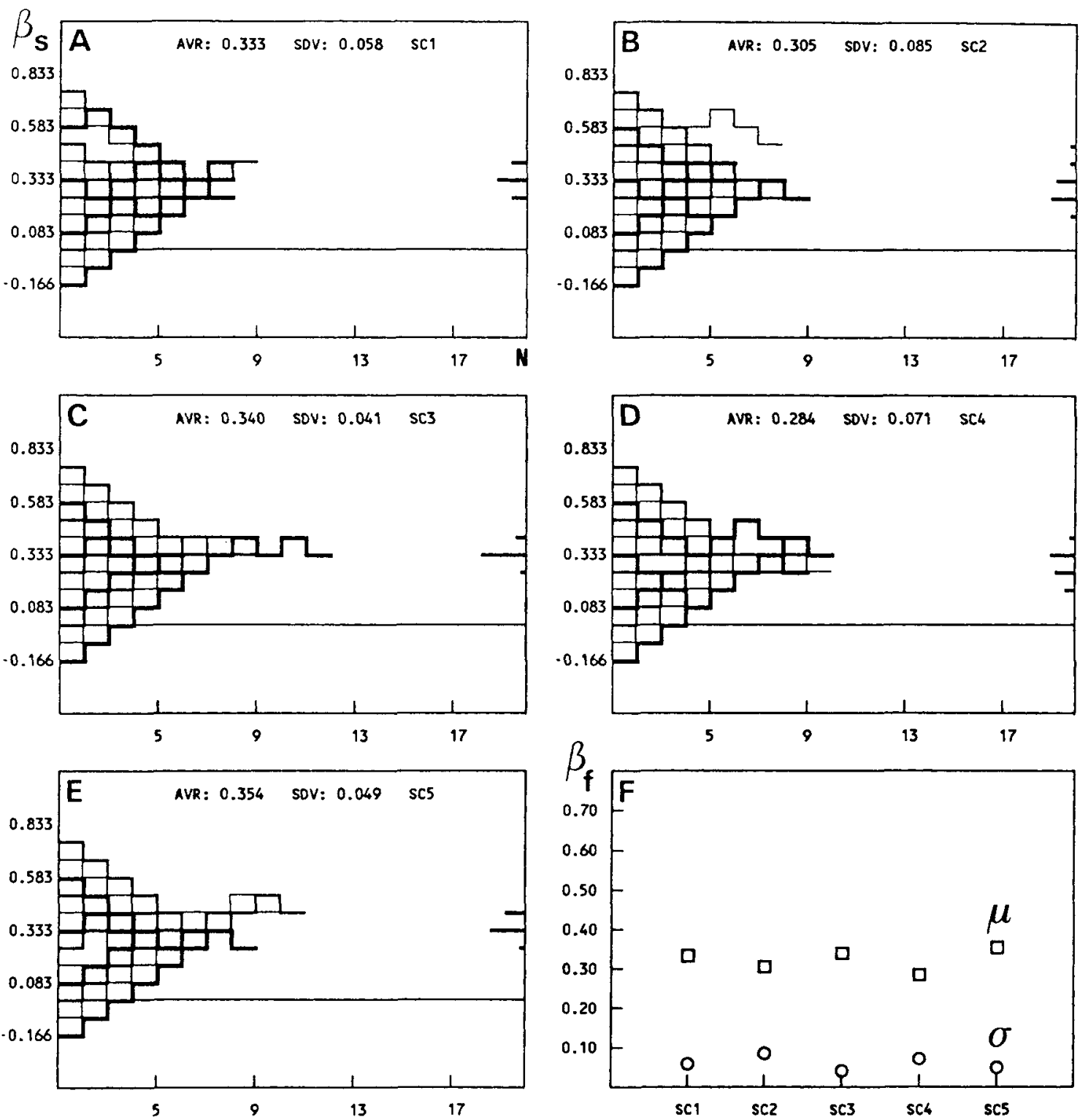

Figure 7. Subjective estimation of uniform velocity: Scribbles. (Results for a typical subject. Staircase plots in Panels A-E [ 1 for each indicated scribble] describe the 12 sequences of $\beta$ values [ 1 for each starting value $\beta_{s}$ ] tested by the subject before reaching a decision. Panel $\mathrm{F}$ depicts averages [squares] and standard deviations [circles]. Notice that horizontal scale is nominal.)

curvature as specified by the two-thirds power law. In other words (cf. Runeson, 1974) subjects may have just labeled "uniform" a class of movements that display the graceful modulations of velocity that are typical of biological motions. Of course, velocity changes as large as those present in scribbles and ellipses when $\beta \approx \frac{1}{3}$ become very salient perceptually if the trajectory is a straight line. The argument is not decisive, however, because straight lines are not typical instances of biological trajectories. Besides, our subjects were never exposed to rectilinear trajectories. We reasoned that if the results of Experiments 1 and 2 were indeed the trivial consequence of a "misunderstanding," it should be possible to obtain different results by replacing a verbal definition of uniformity with a perceptual one. Hence, the gist of the experiment was to provide subjects, before each trial, with examples of constant-velocity motions and to indicate explicitly that judgments on uniformity of velocity should take these examples as a reference.

\section{Method}

Apparatus, test stimuli, and general conditions were the same as in Experiment 2. Eight individuals served as subjects. Three subjects $\left(S_{1}, S_{9}\right.$, and $\left.S_{11}\right)$ had already been tested in Experiments 1 and 2; 5 $\left(S_{14}-S_{18}\right)$ were new (1 man and 4 women). 
Table 3

Influence for Scribbles of the Initial Value of the Exponent $\left(\beta_{s}\right)$ on the Number of Steps Before Reaching a Decision $(N)$ and on the Final Value $\left(\beta_{f}\right)$ : Averages and Standard Deviations Calculated Over All Subjects and Scribbles

\begin{tabular}{cccccccccccccc}
\hline \multirow{2}{*}{$\begin{array}{c}\text { Steps/final } \\
\text { value }\end{array}$} & -.166 & -.083 & .000 & .083 & .166 & .250 & .333 & .416 & .500 & .583 & .666 & .750 \\
\hline$N$ & 7.14 & 6.66 & 5.83 & 5.14 & 4.86 & 4.88 & 4.28 & 4.37 & 4.23 & 5.40 & 5.57 & 6.19 \\
$S D$ & 1.78 & 1.78 & 2.25 & 2.66 & 3.00 & 3.56 & 3.53 & 3.10 & 2.21 & 2.73 & 2.59 & 2.21 \\
& & & & & & & & & & & & \\
$\beta_{f}$ & .291 & .312 & .321 & .333 & .345 & .365 & .372 & .379 & .374 & .378 & .392 & .377 \\
$S D$ & .112 & .094 & .089 & .097 & .084 & .082 & .093 & .085 & .088 & .080 & .097 & .132 \\
\hline
\end{tabular}

\section{Stimuli}

Two types of stimuli were presented in a session. The first type was the same set of five scribbles used previously. Only five $\beta_{s}$ starting values were considered, however: $-.166, .083, .333, .583$, and .833 . The second type was a set of 25 random trajectories obtained by

Table 4

$\beta_{f}$ Values for Each Scribble and Each Subject: Means and Standard Deviations Calculated Over 12 Values (1 for Each Starting Value $\beta_{s}$ )

\begin{tabular}{|c|c|c|c|c|c|}
\hline \multirow[b]{2}{*}{ Subject } & \multicolumn{5}{|c|}{ Scribble } \\
\hline & $\mathrm{SC}_{1}$ & $\mathrm{SC}_{2}$ & $\mathrm{SC}_{3}$ & $\mathrm{SC}_{4}$ & $\mathrm{SC}_{5}$ \\
\hline $\begin{array}{l}\mathbf{S}_{1} \\
S D\end{array}$ & $\begin{array}{l}.444 \\
.092\end{array}$ & $\begin{array}{l}.389 \\
.062\end{array}$ & $\begin{array}{l}.458 \\
.087\end{array}$ & $\begin{array}{l}.410 \\
.099\end{array}$ & $\begin{array}{l}.437 \\
.069\end{array}$ \\
\hline $\begin{array}{l}\mathrm{S}_{2} \\
S D\end{array}$ & $\begin{array}{l}.382 \\
.105\end{array}$ & $\begin{array}{l}.403 \\
.135\end{array}$ & $\begin{array}{l}.389 \\
.119\end{array}$ & $\begin{array}{l}.354 \\
.091\end{array}$ & $\begin{array}{l}.417 \\
.048\end{array}$ \\
\hline $\begin{array}{l}\mathbf{S}_{3} \\
S D\end{array}$ & $\begin{array}{l}.271 \\
.097\end{array}$ & $\begin{array}{l}.243 \\
.041\end{array}$ & $\begin{array}{l}.250 \\
.059\end{array}$ & $\begin{array}{l}.243 \\
.079\end{array}$ & $\begin{array}{l}.257 \\
.086\end{array}$ \\
\hline $\begin{array}{l}\mathrm{S}_{4} \\
S D\end{array}$ & $\begin{array}{l}.423 \\
.105\end{array}$ & $\begin{array}{l}.285 \\
.086\end{array}$ & $\begin{array}{l}.410 \\
.093\end{array}$ & $\begin{array}{l}.347 \\
.095\end{array}$ & $\begin{array}{l}.361 \\
.098\end{array}$ \\
\hline $\begin{array}{l}S_{5} \\
S D\end{array}$ & $\begin{array}{l}.403 \\
.046\end{array}$ & $\begin{array}{l}.319 \\
.095\end{array}$ & $\begin{array}{l}.410 \\
.063\end{array}$ & $\begin{array}{l}.319 \\
.067\end{array}$ & $\begin{array}{l}.326 \\
.053\end{array}$ \\
\hline $\begin{array}{l}\mathrm{S}_{6} \\
S D\end{array}$ & $\begin{array}{l}.354 \\
.108\end{array}$ & $\begin{array}{l}.382 \\
.072\end{array}$ & $\begin{array}{l}.347 \\
.075\end{array}$ & $\begin{array}{l}.347 \\
.089\end{array}$ & $\begin{array}{l}.326 \\
.063\end{array}$ \\
\hline $\begin{array}{l}\mathbf{S}_{7} \\
S D\end{array}$ & $\begin{array}{l}.417 \\
.034\end{array}$ & $\begin{array}{l}.389 \\
.062\end{array}$ & $\begin{array}{l}.403 \\
.046\end{array}$ & $\begin{array}{l}.306 \\
.079\end{array}$ & $\begin{array}{l}.389 \\
.062\end{array}$ \\
\hline $\begin{array}{l}\mathrm{S}_{8} \\
S D\end{array}$ & $\begin{array}{l}.396 \\
.069\end{array}$ & $\begin{array}{l}.375 \\
.120\end{array}$ & $\begin{array}{l}.382 \\
.079\end{array}$ & $\begin{array}{l}.347 \\
.151\end{array}$ & $\begin{array}{l}.403 \\
.082\end{array}$ \\
\hline $\begin{array}{l}S_{9} \\
S D\end{array}$ & $\begin{array}{l}.354 \\
.069\end{array}$ & $\begin{array}{l}.340 \\
.053\end{array}$ & $\begin{array}{l}.354 \\
.050\end{array}$ & $\begin{array}{l}.257 \\
.191\end{array}$ & $\begin{array}{l}.340 \\
.079\end{array}$ \\
\hline $\begin{array}{l}\mathrm{S}_{10} \\
S D\end{array}$ & $\begin{array}{l}.437 \\
.060\end{array}$ & $\begin{array}{l}.375 \\
.054\end{array}$ & $\begin{array}{l}.403 \\
.046\end{array}$ & $\begin{array}{l}.375 \\
.072\end{array}$ & $\begin{array}{l}.361 \\
.039\end{array}$ \\
\hline $\begin{array}{l}S_{11} \\
S D\end{array}$ & $\begin{array}{l}.306 \\
.129\end{array}$ & $\begin{array}{l}.285 \\
.099\end{array}$ & $\begin{array}{l}.319 \\
.082\end{array}$ & $\begin{array}{l}.264 \\
.107\end{array}$ & $\begin{array}{l}.264 \\
.075\end{array}$ \\
\hline $\begin{array}{l}\mathrm{S}_{12} \\
S D\end{array}$ & $\begin{array}{l}.333 \\
.059\end{array}$ & $\begin{array}{l}.306 \\
.086\end{array}$ & $\begin{array}{l}.340 \\
.041\end{array}$ & $\begin{array}{l}.285 \\
.072\end{array}$ & $\begin{array}{l}.354 \\
.050\end{array}$ \\
\hline $\begin{array}{l}S_{13} \\
S D\end{array}$ & $\begin{array}{l}.368 \\
.079\end{array}$ & $\begin{array}{l}.375 \\
.080\end{array}$ & $\begin{array}{l}.361 \\
.086\end{array}$ & $\begin{array}{l}.326 \\
.115\end{array}$ & $\begin{array}{l}.368 \\
.079\end{array}$ \\
\hline
\end{tabular}

concatenating circular arcs with alternating clockwise and counterclockwise directions (Figure 9). The radius of the arcs was constant ( $2 \mathrm{~cm}$ on the screen), and the total length of the trajectory was that of 10 complete circles $(125.66 \mathrm{~cm})$. The length of each arc was selected at random within the interval [1.57-11.94 cm] (i.e., $12.5 \%-95 \%$ of the perimeter). Length selection, however, was constrained stochastically so that the total trajectory occupied approximately the same surface on the screen as the scribbles. Two thousand samples were used to describe the trajectories. With a display rate of $105.3 \mathrm{sps}$, the (constant) velocity was set equal to the average velocity for the five scribbles $(6.61 \mathrm{~cm} / \mathrm{s})$. Duration of the stimuli was $19 \mathrm{~s}$.

\section{Task and Experimental Procedure}

Two blocks (A and B) of 25 trials were administered in one session. The stimuli in Block $A$ were a random permutation of all possible pairings of the five scribbles with the five values of $\beta_{s}$. Presentations and response modalities were as in Experiment 2. The test stimuli in Block B were again a (different) permutation of the same pairings. Before each test stimulus, however, a different constant-velocity trajectory was shown once (a 0.5 -s blank interval separated the end of this display from the start of the test stimuli). Before the sessions, subjects were told explicitly that the displays were examples of random curvilinear trajectories with constant velocity and that they had only a tutorial purpose (no action was required at the end of these displays). The two blocks were separated by a warning message displayed on the screen. As in Experiment 2, the response criterion was stated in terms of most uniform velocity. The 3 subjects already tested before were administered Block A first and then Block B. The order was inverted for the 5 new subjects.

\section{Results and Discussion}

Table 5 reports the final $\beta_{f}$ settings (averages and standard deviations calculated over the five values of $\beta_{s}$ ) for the two experimental blocks (with and without standard). Results from Experiment 2 in 3 Subjects $S_{1}, S_{9}$, and $S_{11}$ are also reported for comparison. The averages of $\beta_{f}$ over subjects, starting values, and scribbles were the following: Block $A$, .381; Block B, .341; Experiment 2, .377. We performed an analysis of variance of $\beta_{f}$ for the 3 old subjects with a 3 (conditions: Block A, Block B, and Experiment 2) $\times 5(\mathrm{SC})$ $\times 5$ (starting values: $\beta_{s}$ ) factorial design and 3 completely repeated measurements per cell $(S)$, which showed no significant effect of the conditions, $F(2,4)=0.11, p=.902$. There were significant effects of $\beta_{s}$ but not of the scribbles: $\beta_{s}, F(4$, $8)=14.51, p=.001 ; \mathrm{SC}, F(4,8)=2.10, p=.173$. A marginal 

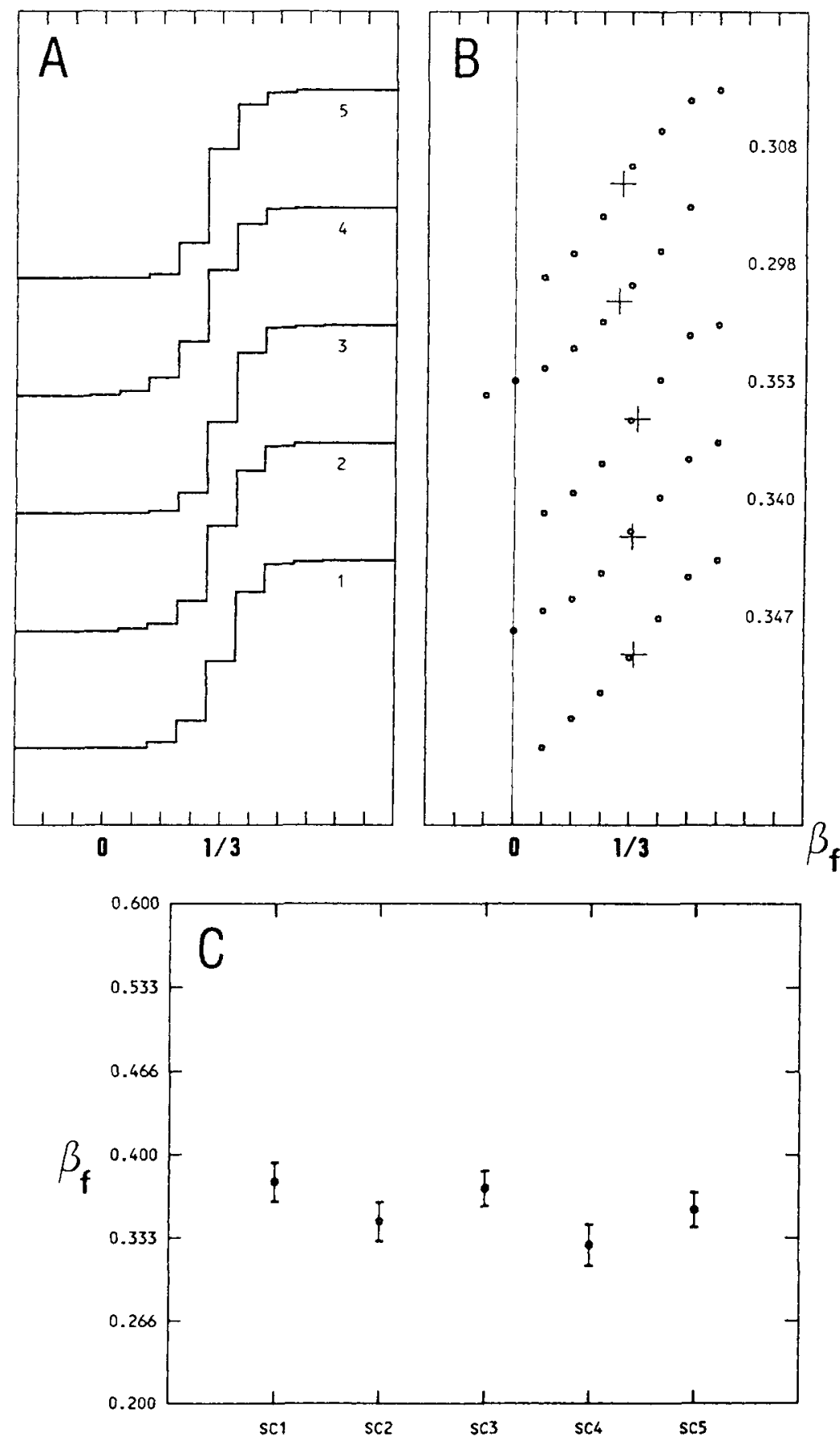

Figure 8. Subjective estimation of uniform velocity: Scribbles. (Results for all subjects. Same format as Figure 6; notice that in Panel $\mathrm{C}$ the horizontal scale is nominal. Numerical values of the means are as follows: $\mathrm{SC}_{1}, .376 ; \mathrm{SC}_{2}, .343 ; \mathrm{SC}_{3}, .371 ; \mathrm{SC}_{4}, .321 ; \mathrm{SC}_{5}, .354$; overall average, .353.)

interaction existed only between conditions and $\beta_{s}, F(8,16)$ $=2.37, p=.068$. An analysis of the 5 new subjects with a 2 (conditions: Block $A$ and Block $\mathrm{B}) \times 5(\mathrm{SC}) \times 5$ (starting values: $\beta_{s}$ ) factorial design and 5 completely repeated measurements per cell $(S)$ showed a significant effect of the conditions, $F(1,4)=28.12, p=.006$, and the scribbles, $F(4,16)$ $=3.66, p=.027$. The difference between the average $\beta_{f}$ over scribbles and subjects for Block A (.393) and Block B (.328) was modest, however. No interaction was significant.

Unlike test scribbles, constant-velocity stimuli were always compatible with the two-thirds power law because the absolute value of their curvature was constant throughout the trajectory. Thus, no interference could arise between the phenomenon under study and the tutorial role assigned to these 


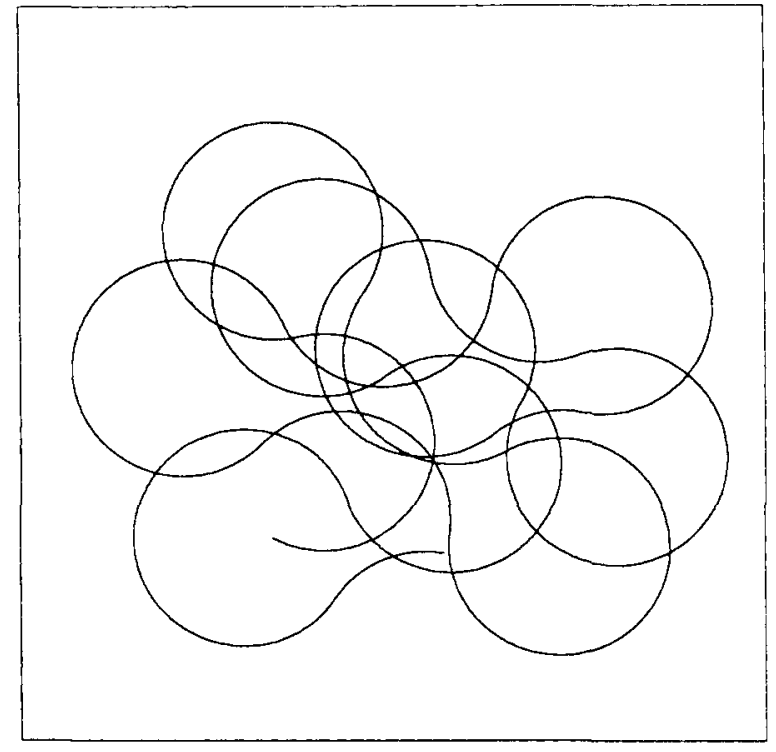

Figure 9. Example of trajectory of the stimuli used in Experiment 3 to demonstrate perceptually the notion of constant velocity.

stimuli. The results of the experiment demonstrate that large misjudgments of velocity persist even when the notion of uniform velocity is explicitly associated with the perceptual representation of a true constant-velocity motion.

\section{Testing the Role of the Stereokinetic Effect}

The stereokinetic (or kinetic depth) effect has long been known (Fisichelli, 1946; Philip \& Fisichelli, 1945; Wallach \& O'Connell, 1953): Whenever a shadow (or an outline) changes in a way that is compatible with a rotation in 3D space of a solid object (or of a frame), a depth sensation is forcefully evoked. The $3 \mathrm{D}$ interpretation overrides the $2 \mathrm{D}$ one even if the latter is much more parsimonious. It has been observed (Mefferd \& Wieland, 1967a, 1967b; Musatti, 1924) that stereokinetic effects are elicited even by rigidly rotating a shape in the frontoparallel plane. More recently, it was demonstrated that a 3D structure can be suggested by displays that consist of unconnected dots (Braunstein, 1962; Börjesson \& von Hofsten, 1972, 1973; Sperling, Landy, Dosher, \& Perkins, 1989; Ullman, 1979; von Hofsten, 1974). Under appropriate conditions, even a single dot may produce the stereokinetic effect (von Hofsten, 1974).

To see why the kinetic depth effect might play a role in our velocity judgments, consider a dot moving at constant velocity along a circular trajectory. If the trajectory is not on the frontoparallel plane, the retinal projection of this distal stimulus is not a circle, and its velocity is not constant. Specifically, let $f$ be the frequency of the movement and $R$ the radius of the circle. Moreover, suppose that the trajectory plane is tilted in the anteroposterior direction by an angle $\theta$. Then, the trajectory of the proximal stimulus is an ellipse with eccentricity $\Sigma=\sin \theta$, and its tangential velocity changes in time according to the Lissajous rule: $V(t)=2 \pi f R\left[\cos ^{2} \theta \cdot \cos ^{2}(2 \pi f t)\right.$ $\left.+\sin ^{2}(2 \pi f t)\right]^{1 / 2}$. In other words, when $\beta=\frac{1}{3}$, the elliptic stimuli can be construed as projections onto a frontoparallel
Table 5

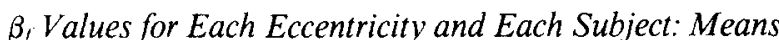
and Standard Deviations Calculated Over 5 Values (1 for Each Starting Value $\beta_{s}$ )

\begin{tabular}{|c|c|c|c|c|c|}
\hline \multirow[b]{2}{*}{ Subject } & \multicolumn{5}{|c|}{ Scribble } \\
\hline & $\mathrm{SC}_{1}$ & $\mathrm{SC}_{2}$ & $\mathrm{SC}_{3}$ & $\mathrm{SC}_{4}$ & $\mathrm{SC}_{5}$ \\
\hline \multicolumn{6}{|c|}{ Experiment 3: Without standard (Block A) } \\
\hline $\begin{array}{l}\mathrm{S}_{1} \\
S D\end{array}$ & $\begin{array}{l}.399 \\
.097\end{array}$ & $\begin{array}{l}.349 \\
.062\end{array}$ & $\begin{array}{l}.349 \\
.062\end{array}$ & $\begin{array}{l}.316 \\
.062\end{array}$ & $\begin{array}{l}.399 \\
.081\end{array}$ \\
\hline $\begin{array}{l}\mathrm{S}_{9} \\
S D\end{array}$ & $\begin{array}{l}.366 \\
.113\end{array}$ & $\begin{array}{l}.333 \\
.000\end{array}$ & $\begin{array}{l}.399 \\
.062\end{array}$ & $\begin{array}{l}.316 \\
.062\end{array}$ & $\begin{array}{l}.333 \\
.074\end{array}$ \\
\hline $\begin{array}{l}S_{11} \\
S D\end{array}$ & $\begin{array}{l}.466 \\
.113\end{array}$ & $\begin{array}{l}.299 \\
.113\end{array}$ & $\begin{array}{l}.416 \\
.105\end{array}$ & $\begin{array}{l}.333 \\
.052\end{array}$ & $\begin{array}{l}.333 \\
.052\end{array}$ \\
\hline $\begin{array}{l}\mathbf{S}_{14} \\
S D\end{array}$ & $\begin{array}{l}.450 \\
.041\end{array}$ & $\begin{array}{l}.283 \\
.085\end{array}$ & $\begin{array}{l}.417 \\
.053\end{array}$ & $\begin{array}{l}.400 \\
.062\end{array}$ & $\begin{array}{l}.367 \\
.041\end{array}$ \\
\hline $\begin{array}{l}\mathbf{S}_{15} \\
S D\end{array}$ & $\begin{array}{l}.367 \\
.067\end{array}$ & $\begin{array}{l}.333 \\
.053\end{array}$ & $\begin{array}{l}.350 \\
.082\end{array}$ & $\begin{array}{l}.350 \\
.062\end{array}$ & $\begin{array}{l}.367 \\
.085\end{array}$ \\
\hline $\begin{array}{l}\mathrm{S}_{16} \\
S D\end{array}$ & $\begin{array}{l}.567 \\
.207\end{array}$ & $\begin{array}{l}.433 \\
.133\end{array}$ & $\begin{array}{l}.450 \\
.041\end{array}$ & $\begin{array}{l}.417 \\
.075\end{array}$ & $\begin{array}{l}.400 \\
.033\end{array}$ \\
\hline $\begin{array}{l}\mathbf{S}_{17} \\
S D\end{array}$ & $\begin{array}{l}.367 \\
.085\end{array}$ & $\begin{array}{l}.367 \\
.085\end{array}$ & $\begin{array}{l}.383 \\
.085\end{array}$ & $\begin{array}{l}.367 \\
.041\end{array}$ & $\begin{array}{l}.300 \\
.067\end{array}$ \\
\hline $\begin{array}{l}S_{18} \\
S D\end{array}$ & $\begin{array}{l}.417 \\
.091\end{array}$ & $\begin{array}{l}.400 \\
.062\end{array}$ & $\begin{array}{l}.417 \\
.053\end{array}$ & $\begin{array}{l}.400 \\
.062\end{array}$ & $\begin{array}{l}.467 \\
.067\end{array}$ \\
\hline Average & .425 & .350 & .398 & .362 & .370 \\
\hline \multicolumn{6}{|c|}{ Experiment 3: With standard (Block B) } \\
\hline $\begin{array}{l}\mathbf{S}_{1} \\
S D\end{array}$ & $\begin{array}{l}.383 \\
.099\end{array}$ & $\begin{array}{l}.349 \\
.110\end{array}$ & $\begin{array}{l}.383 \\
.113\end{array}$ & $\begin{array}{l}.416 \\
.074\end{array}$ & $\begin{array}{l}.416 \\
.052\end{array}$ \\
\hline $\begin{array}{l}S_{9} \\
S D\end{array}$ & $\begin{array}{l}.366 \\
.066\end{array}$ & $\begin{array}{l}.316 \\
.062\end{array}$ & $\begin{array}{l}.333 \\
.052\end{array}$ & $\begin{array}{l}.316 \\
.033\end{array}$ & $\begin{array}{l}.299 \\
.040\end{array}$ \\
\hline $\begin{array}{l}\mathbf{S}_{11} \\
S D\end{array}$ & $\begin{array}{l}.483 \\
.062\end{array}$ & $\begin{array}{l}.333 \\
.158\end{array}$ & $\begin{array}{l}.483 \\
.133\end{array}$ & $\begin{array}{l}.299 \\
.133\end{array}$ & $\begin{array}{l}.266 \\
.062\end{array}$ \\
\hline $\begin{array}{l}\mathrm{S}_{14} \\
S D\end{array}$ & $\begin{array}{l}.400 \\
.097\end{array}$ & $\begin{array}{l}.250 \\
.139\end{array}$ & $\begin{array}{l}.367 \\
.067\end{array}$ & $\begin{array}{l}.317 \\
.097\end{array}$ & $\begin{array}{l}.283 \\
.113\end{array}$ \\
\hline $\begin{array}{l}\mathrm{S}_{15} \\
S D\end{array}$ & $\begin{array}{l}.417 \\
.053\end{array}$ & $\begin{array}{l}.283 \\
.041\end{array}$ & $\begin{array}{l}.333 \\
.053\end{array}$ & $\begin{array}{l}.317 \\
.097\end{array}$ & $\begin{array}{l}.317 \\
.033\end{array}$ \\
\hline $\begin{array}{l}\mathrm{S}_{16} \\
S D\end{array}$ & $\begin{array}{l}.433 \\
.033\end{array}$ & $\begin{array}{l}.400 \\
.033\end{array}$ & $\begin{array}{l}.383 \\
.113\end{array}$ & $\begin{array}{l}.300 \\
.041\end{array}$ & $\begin{array}{l}.367 \\
.100\end{array}$ \\
\hline $\begin{array}{l}\mathrm{S}_{17} \\
S D\end{array}$ & $\begin{array}{l}.250 \\
.139\end{array}$ & $\begin{array}{l}.300 \\
.085\end{array}$ & $\begin{array}{l}.350 \\
.033\end{array}$ & $\begin{array}{l}.250 \\
.091\end{array}$ & $\begin{array}{l}.183 \\
.062\end{array}$ \\
\hline $\begin{array}{l}\mathbf{S}_{18} \\
S D\end{array}$ & $\begin{array}{l}.417 \\
.053\end{array}$ & $\begin{array}{l}.267 \\
.062\end{array}$ & $\begin{array}{l}.317 \\
.082\end{array}$ & $\begin{array}{l}.383 \\
.041\end{array}$ & $\begin{array}{l}.317 \\
.097\end{array}$ \\
\hline Average & .394 & .312 & .369 & .325 & .306 \\
\hline \multicolumn{6}{|c|}{ Experiment 2} \\
\hline $\begin{array}{l}\mathrm{S}_{1} \\
S D\end{array}$ & $\begin{array}{l}.467 \\
.085\end{array}$ & $\begin{array}{l}.433 \\
.122\end{array}$ & $\begin{array}{l}.433 \\
.097\end{array}$ & $\begin{array}{l}.417 \\
.149\end{array}$ & $\begin{array}{l}.417 \\
.075\end{array}$ \\
\hline $\begin{array}{l}\mathrm{S}_{9} \\
S D\end{array}$ & $\begin{array}{l}.450 \\
.100\end{array}$ & $\begin{array}{l}.400 \\
.097\end{array}$ & $\begin{array}{l}.400 \\
.097\end{array}$ & $\begin{array}{l}.350 \\
.082\end{array}$ & $\begin{array}{l}.383 \\
.066\end{array}$ \\
\hline $\begin{array}{l}\mathrm{S}_{11} \\
S D\end{array}$ & $\begin{array}{l}.283 \\
.085\end{array}$ & $\begin{array}{l}.367 \\
.113\end{array}$ & $\begin{array}{l}.317 \\
.143\end{array}$ & $\begin{array}{l}.250 \\
.158\end{array}$ & $\begin{array}{l}.283 \\
.124\end{array}$ \\
\hline Average & .400 & .400 & .383 & .339 & .361 \\
\hline
\end{tabular}

Note. For Experiment 2, only the results for the same values of $\beta_{s}$ were averaged. 
plane of a 3D event with uniform velocity. One could then argue that misjudgments in Experiment 1 occurred because viewers adopted this interpretation and referred their velocity judgments to the distal stimulus rather than the proximal one.

Two objections can be raised against this argument. First, a lawful 3D interpretation of the elliptic trajectory exists only when $\beta=\frac{1}{3}$. For all other values, velocity profile and eccentricity are mutually inconsistent. Second, an explanation of the effects in purely visual terms seems barred by the results of Experiment 2. In fact, unlike ellipses, no simple 3D shape exists that projects on a plane like our scribbles. Yet, the estimates of $\beta_{f}$ for scribbles are actually higher than those for ellipses. It is somewhat unlikely that similar effects in the two experiments have different causes. A further, more decisive way to exclude a role of the kinetic depth effect is to replicate Experiments 1 and 2 by using modified versions of the stimuli for which a 3D interpretation is virtually impossible. Experiments 4-6 were designed for this purpose.

\section{Experiment 4}

\section{Method}

Apparatus, assignment, scheduling of the trials, and general conditions were as in Experiment 1 . Three individuals $\left(\mathbf{S}_{1}, \mathbf{S}_{9}\right.$, and $\left.\mathbf{S}_{11}\right)$ who had already been tested in Experiments 1 and 2 served as subjecıs.

\section{Stimuli}

A continuous white line divided the computer screen at about one third of the screen height from the bottom. A light spot (brighter than the line) bounced back and forth on this line (in the upper part of the screen) following a trajectory that was one half of an ellipse. In one condition $(H)$, the ellipse was bisected along the major axis. In another condition $(V)$, it was bisected along the minor axis. In both cases, the eccentricity $\Sigma$ could take the same seven values as in Experiment 1. Sample density (400 points for half an ellipse) and display rate (207.8 sps) were also identical. As usual, the kinematics of the motion was controlled by the single parameter $\beta$. The initial value $\beta_{s}$ could take one of the following six values: $-.333,-.083$, $.166, .416, .666$, or 916 . A session comprised $7(\Sigma) \times 6\left(\beta_{s}\right) \times 2(H /$ $V)=84$ trials. The order of presentation of the trials was randomized for each subject.

\section{Results and Discussion}

Table 6 reports averages and standard deviations (computed over $\beta_{s}$ ) of the final $\beta_{f}$ settings for the two orientations and for each subject. Results from Experiment 1 in the same 3 subjects are also reported for comparison. The average of $\beta_{f}$ over subjects, starting values, and eccentricities were the following: $H, .259$ ( \pm .197$) ; V, .168( \pm .154)$; Experiment $1, .147$ ( \pm .104$)$. An analysis of variance of $\beta_{f}$ with a 3 (conditions: $H$, $V$, and Experiment 1) $\times 7$ (eccentricities: $\Sigma) \times 6$ (starting

Table 6

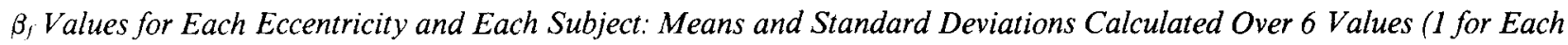
Starting Value $\beta_{s}$ )

\begin{tabular}{|c|c|c|c|c|c|c|c|}
\hline \multirow[b]{2}{*}{ Subject } & \multicolumn{7}{|c|}{ Eccentricity } \\
\hline & $\begin{array}{c}527 \\
\left(B_{y} / B_{x}=.850\right)\end{array}$ & $\begin{array}{c}.661 \\
\left(B_{y} / B_{x}=.750\right) \\
\end{array}$ & $\begin{array}{c}.760 \\
\left(B_{y} / B_{x}=.650\right)\end{array}$ & $\begin{array}{c}.835 \\
\left(B_{y} / B_{x}=.550\right) \\
\end{array}$ & $\begin{array}{c}.893 \\
\left(B_{y} / B_{x}=.450\right) \\
\end{array}$ & $\begin{array}{c}.936 \\
\left(B_{y} / B_{x}=.350\right) \\
\end{array}$ & $\begin{array}{c}.968 \\
\left(B_{y} / B_{x}=.250\right)\end{array}$ \\
\hline \multicolumn{8}{|c|}{ Experiment 4: Condition $H$} \\
\hline $\begin{array}{l}\mathrm{S}_{1} \\
S D\end{array}$ & $\begin{array}{l}.348 \\
.122\end{array}$ & $\begin{array}{l}.292 \\
.165\end{array}$ & $\begin{array}{l}.278 \\
.124\end{array}$ & $\begin{array}{l}.431 \\
.294\end{array}$ & $\begin{array}{l}.348 \\
.270\end{array}$ & $\begin{array}{l}.431 \\
.089\end{array}$ & $\begin{array}{l}.223 \\
.372\end{array}$ \\
\hline $\begin{array}{l}S_{9} \\
S D\end{array}$ & $\begin{array}{l}.223 \\
.039\end{array}$ & $\begin{array}{l}.223 \\
.062\end{array}$ & $\begin{array}{l}.223 \\
.039\end{array}$ & $\begin{array}{l}.250 \\
.068\end{array}$ & $\begin{array}{l}.208 \\
.080\end{array}$ & $\begin{array}{l}.208 \\
.080\end{array}$ & $\begin{array}{l}.292 \\
.258\end{array}$ \\
\hline $\begin{array}{l}\mathrm{S}_{11} \\
S D\end{array}$ & $\begin{array}{l}.167 \\
.048\end{array}$ & $\begin{array}{l}.167 \\
.048\end{array}$ & $\begin{array}{l}.208 \\
.134\end{array}$ & $\begin{array}{l}.194 \\
.178 \\
\end{array}$ & $\begin{array}{l}.278 \\
.062 \\
\end{array}$ & $\begin{array}{l}.264 \\
.112 \\
\end{array}$ & $\begin{array}{l}.194 \\
.413 \\
\end{array}$ \\
\hline \multicolumn{8}{|c|}{ Experiment 4: Condition $V$} \\
\hline $\begin{array}{l}\mathrm{S}_{1} \\
S D\end{array}$ & $\begin{array}{l}.208 \\
.080\end{array}$ & $\begin{array}{l}.181 \\
.089\end{array}$ & $\begin{array}{l}.194 \\
.092\end{array}$ & $\begin{array}{l}.069 \\
.101\end{array}$ & $\begin{array}{l}.042 \\
.249\end{array}$ & $\begin{array}{l}.111 \\
.062\end{array}$ & $\begin{array}{l}.250 \\
.337\end{array}$ \\
\hline $\begin{array}{l}\mathrm{S}_{4} \\
S D\end{array}$ & $\begin{array}{l}.236 \\
.031\end{array}$ & $\begin{array}{l}.181 \\
.031\end{array}$ & $\begin{array}{l}.194 \\
.062\end{array}$ & $\begin{array}{l}.069 \\
.057\end{array}$ & $\begin{array}{l}.153 \\
.075\end{array}$ & $\begin{array}{l}.153 \\
.075\end{array}$ & $\begin{array}{l}.069 \\
.252\end{array}$ \\
\hline $\begin{array}{l}\mathrm{S}_{11} \\
S D\end{array}$ & $\begin{array}{l}.250 \\
.048 \\
\end{array}$ & $\begin{array}{l}.194 \\
.092 \\
\end{array}$ & $\begin{array}{l}.250 \\
.048 \\
\end{array}$ & $\begin{array}{l}.235 \\
.049 \\
\end{array}$ & $\begin{array}{l}.208 \\
.244 \\
\end{array}$ & $\begin{array}{l}.111 \\
.062 \\
\end{array}$ & $\begin{array}{l}.181 \\
.170 \\
\end{array}$ \\
\hline \multicolumn{8}{|c|}{ Experiment 1} \\
\hline $\begin{array}{l}\mathrm{S}_{1} \\
S D\end{array}$ & $\begin{array}{l}.153 \\
.057\end{array}$ & $\begin{array}{l}.153 \\
.031\end{array}$ & $\begin{array}{l}.153 \\
.031\end{array}$ & $\begin{array}{r}.153 \\
.057\end{array}$ & $\begin{array}{l}.083 \\
.107\end{array}$ & $\begin{array}{l}.069 \\
.155\end{array}$ & $\begin{array}{l}.042 \\
.219\end{array}$ \\
\hline $\begin{array}{l}\mathrm{S}_{4} \\
S D\end{array}$ & $\begin{array}{l}.167 \\
.000\end{array}$ & $\begin{array}{l}.153 \\
.031\end{array}$ & $\begin{array}{l}.139 \\
.040\end{array}$ & $\begin{array}{l}.111 \\
.040\end{array}$ & $\begin{array}{l}.111 \\
.040\end{array}$ & $\begin{array}{l}.125 \\
.042\end{array}$ & $\begin{array}{l}.153 \\
.139\end{array}$ \\
\hline $\begin{array}{l}\mathrm{S}_{11} \\
S D\end{array}$ & $\begin{array}{l}.181 \\
.057\end{array}$ & $\begin{array}{l}.181 \\
.031\end{array}$ & $\begin{array}{l}.194 \\
.040\end{array}$ & $\begin{array}{l}.208 \\
.125\end{array}$ & $\begin{array}{l}.194 \\
.078\end{array}$ & $\begin{array}{l}.139 \\
.104\end{array}$ & $\begin{array}{l}.236 \\
.163\end{array}$ \\
\hline
\end{tabular}

Note. For Experiment 1, only the results for the same values of $\beta_{s}$ have been averaged. $B_{y} / B_{x}$ denotes the semiaxis ratio of the ellipse. 
values: $\beta_{s}$ ) factorial design and 3 completely repeated measurements per cell $(S)$ showed a significant effect of the starting value, $F(5,10)=8.31, p=.002$. Eccentricity had no significant effect, $F(6,12)=.97, p=.486$. An interaction was present only between eccentricity and $\beta_{s}, F(30,60)=3.52, p$ $<.001$. As in Experiment 1 , this interaction is entirely due to the results for the smaller eccentricity $\Sigma=.527$.

In both orientations $(H$ and $V$ ) and for all values of $\beta$, the stimuli forcefully evoked the image of an elastic object bouncing back and forth between two points on the ground. Apparently, the presence of rebounds at the points of discontinuity overrides the large discrepancies that exist between the kinematics of the stimuli and that of a real physical event. The discrepancy is particularly striking in Condition $H$ for positive values of $\beta$ (this, however, did not prevent Aristotle from claiming that objects thrown in the air reach their maximum speed at the midpoint of their trajectory). Whatever the value of $\beta$, the possibility of interpreting the stimuli as plane projections of $3 \mathrm{D}$ events was remote for $V$-type stimuli and nonexistent for $H$-type stimuli. Nevertheless, in all subjects the averages of $\beta_{f}$ over all eccentricities in this experiment were higher than those in Experiment 1. Moreover, averages for Condition $H$ were considerably higher than those for Condition $V$. Thus, in contrast with the hypothesis that misjudgments of velocity are in fact veridical judgments in 3D space, the perceptual effect actually got bigger when $3 \mathrm{D}$ interpretations of the stimuli were made more improbable.

A possible reason for the difference between the results in Conditions $H$ and $V$ is the fact that velocities in the vertical direction are overestimated by as much as $30 \%$ with respect to the horizontal direction (Brown, 1931, Table 10). Thus, for any combination of $\beta$ and $\Sigma$ values, the portions of the trajectories with lower curvature appear to be faster in Condition $V$ than in Condition $H$. Because of Equation 1, however, subjects could compensate for this unbalance by decreasing $\beta$ in Condition $V$. For instance, suppose that $\alpha=0$. Then, for any two values $\beta_{1}$ and $\beta_{2}$, the ratio of the corresponding velocities at the point of least curvature is $r=\left(B_{x}^{2} / B_{y}\right)^{\beta_{1}-\beta_{2}}$. For $\Sigma=.9, B_{x}=6.4, \beta_{1}=.259$, and $\beta_{2}=.168$, this gives $r=$ 1.28 , in excellent agreement with the size of the directional bias measured by Brown.

\section{Experiments 5 and 6}

\section{Method}

Apparatus, assignment, scheduling of the trials, and general conditions were as in Experiments 1 and 2. Six individuals served as subjects. Three $\left(S_{6}, S_{11}\right.$, and $\left.S_{12}\right)$ had already been tested in Experiments 1 and 2; the other three $\left(S_{14}, S_{15}\right.$, and $\left.S_{16}\right)$ had been tested in Experiment 3

\section{Stimuli, Task, and Experimental Procedure}

Stimuli for Experiment 5 were the same seven ellipses used for Experiment 1, but the number of initial $\beta_{s}$ values was reduced to five: $-.333,-.083, .166, .416$, and .666 (35 trials). Stimuli for Experiment 6 were the same pairings of five scribbles and five initial $\beta_{s}$ values used for Block $A$ of Experiment 3 ( 25 trials). Experiments were run in a single session and in different days. In both experiments, the display program was modified so that the visible stimulus at any one time during a trial consisted of a $2.5-\mathrm{cm}$ segment of trajectory. The leading edge of the segment satisfied Equation 2 and was slightly highlighted. The trailing edge had the same velocity of the leading one; however, because it lagged by a constant linear extent along the trajectory, it violated Equation 2 by an amount that depended on the curvature gradient of the path. According to the subjects, stimuli evoked speeded-up recordings of a crawling snake. Phenomenally, the presence of a visible segment enhanced the flatness of the display. The assignment was similar to that of Experiments 1 and 2, with the only difference being that subjects were encouraged to focus attention on the highlighted leading edge of the segment. Notice that even when pursuing this edge with a stable fixation, the rest of the segment remained clearly visible.

\section{Results and Discussion}

Table 7 reports the results of Experiment 5 . Averages and standard deviations of the final $\beta_{f}$ settings are indicated for each subject and each eccentricity, calculated over the five values of $\beta_{s}$. The mean of individual averages of $\beta_{f}$ over eccentricity and starting values was .176 . An analysis of variance on the data of the 3 subjects who had already served in Experiment 1 with a 2 (conditions: Experiment 1 and Experiment 5) $\times 7$ (eccentricities: $\Sigma) \times 5$ (starting values: $\beta_{s}$ ) factorial design and 3 completely repeated measurements per cell $(S)$ failed to detect a significant effect of condition, $F(1$, $2)=.19, p=.704$. Table 8 reports the analogous results from Experiment 6 . The mean of individual averages of $\beta_{f}$ over starting values and scribbles was .313. An analysis of variance on the data of the 3 subjects who had already served in Experiment 2 with a 2 (conditions: Experiment 2 and Experiment 6$) \times 5(\mathrm{SC}) \times 5$ (starting values: $\beta_{\text {s }}$ ) factorial design and 3 completely repeated measurements per cell $(S)$ again failed to detect a significant effect of condition, $F(1,2)=.15$, $p=.734$. We did not observe significant differences between old and new subjects in either Experiment 5 or Experiment 6. Moreover, both overall means of $\beta_{f}$ were very close to the corresponding means in Experiments 1 and 2 (see Panel $\mathrm{C}$ of Figures 6 and 8 ). In conclusion, these two last controls confirm fully the conclusions of the main experiments, namely the presence of a large misjudgment of velocity and the difference between ellipses and scribbles.

\section{General Discussion}

A class of 2D movements appear to be uniform even though their tangential velocity varies by as much as $200 \%$ (Experiments 1 and 2). The phenomenon cannot be explained away by semantic ambiguities (Experiment 3 ); moreover, it persists even when no physical 3D scenario can be envisaged within which our perceptual judgment would be veridical (Experiment 4 ) or when the nature of the stimuli enhances the $2 \mathrm{D}$ nature of the display (Experiments 5 and 6). Therefore, it is appropriate to consider this phenomenon as a bona fide dynamic illusion. The class of movements for which the illusion occurs is a specific subset of all physical point motions, and includes in particular 2D endpoint drawing movements. The subset can be characterized in a fairly accurate way by a one-parameter criterion. The pattern of results vis à vis this criterion supports the contention that visual percep- 
Table 7

$\beta_{f}$ Values for Each Eccentricity and Each Subject: Means and Standard Deviations Calculated Over 5 Values (1 for Each Starting Value $\beta_{s}$ )

\begin{tabular}{|c|c|c|c|c|c|c|c|}
\hline \multirow[b]{2}{*}{ Subject } & \multicolumn{7}{|c|}{ Eccentricity } \\
\hline & $\begin{array}{c}.527 \\
\left(B_{y} / B_{x}=.850\right)\end{array}$ & $\begin{array}{c}.661 \\
\left(B_{y} / B_{x}=.750\right)\end{array}$ & $\begin{array}{c}.760 \\
\left(B_{y} / B_{x}=.650\right) \\
\end{array}$ & $\begin{array}{c}.835 \\
\left(B_{y} / B_{x}=.550\right)\end{array}$ & $\begin{array}{c}.893 \\
\left(B_{y} / B_{x}=.450\right)\end{array}$ & $\begin{array}{c}.936 \\
\left(B_{y} / B_{x}=.350\right)\end{array}$ & $\begin{array}{c}.968 \\
\left(B_{y} / B_{x}=.250\right) \\
\end{array}$ \\
\hline $\begin{array}{l}\mathrm{S}_{6} \\
S D\end{array}$ & $\begin{array}{l}.117 \\
.041\end{array}$ & $\begin{array}{l}.167 \\
.053\end{array}$ & $\begin{array}{l}.133 \\
.041\end{array}$ & $\begin{array}{l}.150 \\
.033\end{array}$ & $\begin{array}{l}.150 \\
.062\end{array}$ & $\begin{array}{l}.217 \\
.155\end{array}$ & $\begin{array}{l}.150 \\
.531\end{array}$ \\
\hline $\begin{array}{l}\mathrm{S}_{11} \\
S D\end{array}$ & $\begin{array}{l}.200 \\
.041\end{array}$ & $\begin{array}{l}.183 \\
.062\end{array}$ & $\begin{array}{l}.217 \\
.067\end{array}$ & $\begin{array}{l}.217 \\
.135\end{array}$ & $\begin{array}{l}.167 \\
.118\end{array}$ & $\begin{array}{l}.183 \\
.170\end{array}$ & $\begin{array}{l}.217 \\
.375\end{array}$ \\
\hline $\begin{array}{l}\mathrm{S}_{12} \\
S D\end{array}$ & $\begin{array}{l}.117 \\
.085\end{array}$ & $\begin{array}{l}.150 \\
.062\end{array}$ & $\begin{array}{l}.183 \\
.033\end{array}$ & $\begin{array}{l}.200 \\
.041\end{array}$ & $\begin{array}{l}.217 \\
.041\end{array}$ & $\begin{array}{l}.200 \\
.041\end{array}$ & $\begin{array}{l}.200 \\
.041\end{array}$ \\
\hline $\begin{array}{l}\mathrm{S}_{14} \\
S D\end{array}$ & $\begin{array}{l}.217 \\
.041\end{array}$ & $\begin{array}{l}.217 \\
.041\end{array}$ & $\begin{array}{l}.183 \\
.062\end{array}$ & $\begin{array}{l}.167 \\
.000\end{array}$ & $\begin{array}{l}.167 \\
.091\end{array}$ & $\begin{array}{l}.200 \\
.194\end{array}$ & $\begin{array}{l}.133 \\
.310\end{array}$ \\
\hline $\begin{array}{l}\mathrm{S}_{15} \\
S D\end{array}$ & $\begin{array}{l}.217 \\
.041\end{array}$ & $\begin{array}{l}.183 \\
.033\end{array}$ & $\begin{array}{l}.217 \\
.041\end{array}$ & $\begin{array}{l}.217 \\
.041\end{array}$ & $\begin{array}{l}.200 \\
.085\end{array}$ & $\begin{array}{l}.167 \\
.075\end{array}$ & $\begin{array}{l}.117 \\
.180\end{array}$ \\
\hline $\begin{array}{l}S_{16} \\
S D\end{array}$ & $\begin{array}{l}.200 \\
.067\end{array}$ & $\begin{array}{l}.250 \\
.000\end{array}$ & $\begin{array}{l}.217 \\
.041\end{array}$ & $\begin{array}{l}.200 \\
.041\end{array}$ & $\begin{array}{l}.167 \\
.075\end{array}$ & $\begin{array}{l}.183 \\
.193\end{array}$ & $\begin{array}{l}.200 \\
.332\end{array}$ \\
\hline Average & .117 & .192 & .192 & .192 & .178 & .192 & .170 \\
\hline
\end{tabular}

Note. $B_{y} / B_{x}$ denotes the semiaxis ratio of the ellipse.

tion of dynamic events is influenced by the intrinsic properties of the motor system. In what follows we qualify this contention.

\section{Motor-Perceptual Interactions}

Our interpretation of the results entails two conceptual steps. First, there is the assumption that perceptual mechanisms have access to an internal representation of the con-

Table 8

$\beta_{f}$ Values for Each Scribble and Each Subject: Means and Standard Deviations Calculated Over 5 Values (1 for Each Starting Value $\beta_{s}$ )

\begin{tabular}{lccccc}
\hline & \multicolumn{5}{c}{ Scribble } \\
\cline { 2 - 6 } Subject & $\mathrm{SC}_{1}$ & $\mathrm{SC}_{2}$ & $\mathrm{SC}_{3}$ & $\mathrm{SC}_{4}$ & $\mathrm{SC}_{5}$ \\
\hline $\mathrm{S}_{6}$ & .150 & .217 & .233 & .133 & .183 \\
$S D$ & .062 & .100 & .082 & .113 & .062 \\
& & & & & \\
$\mathrm{~S}_{11}$ & .333 & .333 & .300 & .400 & .350 \\
$S D$ & .105 & .230 & .155 & .207 & .295 \\
$\mathrm{~S}_{12}$ & .317 & .417 & .383 & .367 & .333 \\
$S D$ & .062 & .000 & .041 & .041 & .053 \\
$\mathrm{~S}_{14}$ & .333 & .300 & .417 & .267 & .300 \\
$S D$ & .105 & .113 & .118 & .122 & .085 \\
$\mathrm{~S}_{15}$ & .300 & .350 & .367 & .300 & .350 \\
$S D$ & .067 & .097 & .085 & .125 & .143 \\
$\mathrm{~S}_{16}$ & .283 & .250 & .350 & .383 & .400 \\
$S D$ & .085 & .053 & .153 & .085 & .097 \\
Average & .286 & .311 & .342 & .308 & .319 \\
\hline
\end{tabular}

straint expressed by Equation 1, which characterizes most instances of biological (2D, endpoint) motion. Second, there is the further assumption that for some reason, these biological motions are perceived as being uniform. The first step is just a qualification of a more general view put forward by several authors to explain the great sensitivity with which we perceive gait and other postural movements (see the introduction and later). The second step might have concealed a problem of terminology. Such a possibility, however, was ruled out by the demonstration (Experiment 3) that extensive tutoring with true constant-velocity motions failed to reduce the size of the illusion. Logically, the status of the two steps is somewhat different insofar as the second one presupposes the first but not vice versa. Indeed, we could have access to an internal representation of biological motion that is based on motor information and yet perceive the kinematics of this motion veridically. In other words, in a logically acceptable albeit counterfactual scenario, we could be very good at discriminating biological motions, yet reckon the fact that in general, the velocity of these motions is not constant. By contrast, for us to display the observed selective misjudgment of kinematics, we must necessarily have the capability of discriminating with great accuracy the specific relational feature that characterizes biological motion.

The size of the illusion seems to depend on the distribution of curvature along the trajectories. In fact, in Experiment 1 the $\mathrm{CE}$ increases with the eccentricity of the ellipses (see Figure 6). Moreover, the $\mathrm{CE}$ is uniformly lower for ellipses than for scribbles that cover a broader range of curvature values and include more segments with high curvature (Figure 3). Although people seem to perform poorly in judging dynamic systems in which angular momentum is relevant (Proffitt \& Gilden, 1989), such a dependency suggests nevertheless a role of angular variables. In fact, let $A=V / R$ be the angular 
velocity of the movement, and assume for simplicity that $\alpha$ $=0$. Equation 1 can then be written in two equivalent forms (see the introduction): $V=K R^{\beta}$, and $A=K R^{\beta-1}$. Thus, $d V /$ $d R=K \beta R^{\beta-1}$, and $d A / d R=K(\beta-1) R^{\beta-2}$. For $0 \leq \beta \leq 1$, $d V / d R \geq 0$ and $d A / d R \leq 0$. Moreover, it can be shown that in the range $1 / e \leq R \leq e$ (relatively high curvatures), by increasing $\beta$ one increases the (positive) derivative $d V / d R$ and at the same time decreases the absolute value of the (negative) derivative $d A / d R$; when $\beta=0, V$ is constant, and $A$ is inversely proportional to the radius. Conversely, when $\beta=1, V$ is proportional to the radius, and the angular velocity is constant. Therefore, the values of $\beta$ selected by all subjects indicate that perceived velocity results from compounding both tangential and angular components of the velocity vector field associated with the stimuli. If so, the parameter $\beta$ would be adjusted to minimize the average absolute variation of this compounded quantity. Of course, the fact that (at least in the scribble experiments) the selected $\beta$ s correspond almost precisely with the experimental value of the two-thirds power law does not imply that natural movements minimize the variations of the same compounded quantity supposedly used for perceptual judgments. It does mean, however, that whatever the criterion on which velocity judgments are based, this criterion reflects a property of actual voluntary movements. Thus, in selecting the most uniform law of motion, we end up discriminating acceptable instances of biological motion.

\section{Perceptual Learning}

We have presented a number of reasons to believe that our discrimination power hinges on implicit knowledge about the working of the motor system. Let us now consider the possibility that discriminability is instead the result of perceptual learning. The main reason to downplay the role of perceptual learning is the so-called poverty-of-the-stimulus argument already invoked in other contexts to argue that certain cognitive competencies are actually inborn faculties (e.g., Liberman \& Mattingly, 1985; Lightfoot, 1987). No doubt there are plenty of occasions, even early in life, to see instances of biological motions. However, for us to acquire through learning a tuning to the critical $\beta$ value as sharp as that documented by Experiments 2, 4 , and 6 , the perceptual correlate of the distal event should bear a quantitatively consistent relation to the exponent of the two-thirds power law. This would indeed be the case if we were only exposed to parallel projections in the frontal plane of $2 \mathrm{D}$ endpoint movements. Instead, we generally look at 3D movements from all kinds of different perspectives. Thus, geometry and kinematics of the proximal stimulus do not relate in any constant manner and can hardly provide the basis for a learning process.

Perspective distortions do not necessarily constitute a problem. Tenants of the Gibsonian doctrine would object that the covariance expressed by the two-thirds power law may be accessed directly by the perceptual system (cf. Todd, 1984). The objection, however, cannot be used to rescue the learning hypothesis. In fact, direct perception à la Gibson does imply the existence of inborn mechanisms selectively attuned to this peculiar form of covariation. Notice that in all cases, that is, even under ideal conditions (see the preceding paragraphs), the distortion of kinematics that affects the perception of biological movements seems incompatible with the possibility of discriminating through learning the specific covariation of velocity and curvature expressed by Equation 1.

Finally, circumstantial evidence against the learning hypothesis comes from an experiment by Beardworth and Bukner (1981). By using the display technique introduced by Johansson (1973, 1977), these authors demonstrated that we are better at identifying our own walking than that of close friends even though we see them walking much more frequently than we see ourselves. Despite the obvious differences with our experiments, this result points to a similar conclusion, namely that when it comes to handling biological motion, the perceptual system brings to bear an internalized representation of our motor competencies.

Rejection of the perceptual learning hypothesis does not imply ipso facto that the internal representation of motor competencies is innate. Clearly, the ontogenetic problem cannot be addressed directly on the basis of our results. Note, however, that a developmental study of drawing movements (Viviani \& Schneider, 1991) has shown that already at the age of 5 , curvature and velocity are related by a power law. The age-dependent trend in the exponent of this law suggests that a covariation of geometry and kinematics already exists at birth and that the effect of age is mainly to bring the exponent to its final-state value sometimes before puberty. Moreover, we also recall that certain perceptual competencies related to body movements seem to be in place in the very early stages of infancy (Bertenthal et al., 1984; Bertenthal et al., 1987). Thus, pending future investigations, the safest position on the ontogenetic issue seems to be that the bases for motorperceptual interactions may be innate, but the emergence of these effects is conditioned by maturational processes.

\section{References}

Beardworth, T., \& Bukner, T. (1981). The ability to recognize oneself from a video recording of one's movement without one's body. Bulletin of the Psychonomic Society, 18, 19-22.

Bertenthal, B. I., Proffitt, D. R., \& Cutting, J. (1984). Infant sensitivity to figural coherence in biomechanical motion. Journal of Experimental Child Psychology, 37, 213-230.

Bertenthal, B. I., Proffitt, D. R., \& Kramer, S. J. (1987). Perception of biomechanical motion by infants: Implementation of various processing constraints. Journal of Experimental Psychology: $\mathrm{Hu}$ man Perception and Performance, 13, 577-585.

Börjesson, E., \& von Hofsten, C. (1972). Spatial determinants of depth perception in two-dot motion patterns. Perception \& Psychophysics, 11, 263-268.

Börjesson, E., \& von Hofsten, C. (1973). Visual perception of motion in depth: Application of a vector model to three-dot motion patterns. Perception \& Psychophysics, 13, 169-179.

Braunstein, M. L. (1962). Depth perception in rotating dot patterns: Effects of numerosity and perspective. Journal of Experimental Psychology, 64, 415-420.

Brown, J. F. (1931). The visual perception of velocity. Psychologische Forschung, 14, 199-232.

Cohen, R. L. (1964). Problems in motor perception. Uppsala, Sweden: Lundquistska Bokhandeln.

Coren, S., \& Girgus, J. S. (1978a). Seeing is deceiving: The psychology 
of visual illusion. Hillsdale, NJ: Erlbaum.

Coren, S., \& Girgus, J. S. (1978b). Visual illusions. In R. Held, H. W. Leibowitz, \& H.-L. Teuber (Eds.), Handbook of sensory physiology: Vol. 8. Perception (pp. 549-568). New York: SpringerVerlag.

Cutting, J. E. (1981). Coding theory adapted to gait perception. Journal of Experimental Psychology: Human Perception and Performance, 7, 71-87.

Cutting, J. E., \& Proffitt, D. R. (1981). Gait perception as an example of how we may perceive events. In R. Walk \& F. L. Pick (Eds.), Intersensory perception and sensory integration (pp. 249-273). New York: Plenum Press.

Fisichelli, V. R. (1946). Effect of rotational axis and dimensional variations on the reversals of apparent movement in Lissajous figures. American Journal of Psychology, 59, 669-675.

Freyd. J. J. (1987). Dynamic mental representation. Psychological Review: 94, 427-438.

Freyd, J. J., Pantzer. T. M., \& Cheng, J. L. (1988). Representing statics as forces in equilibrium. Journal of Experimental Psychology: General, 117, 395-407.

Goldstein, J., \& Wiener, C. (1963). On some relations between the perception of depth and of movement. Journal of Psychology, 55, $3-23$.

Hoffman, D. D., \& Flinchbaugh, B. E. (1982). The interpretation of biological motion. Biological Cybernetics, 42, 195-204.

Johansson. G. (1950). Configurations in events perception. Uppsala, Sweden: Almqvist \& Wiksell.

Johansson, G. (1973). Visual perception of biological motion and a model for its analysis. Perception \& Psychophysics, 14, 201-211.

Johansson, G. (1977). Studies on visual perception of locomotion. Perception, 6, 365-376.

Lacquaniti, F. Terzuolo, C. A., \& Viviani, P. (1983). The law relating kinematic and figural aspects of drawing movements. Acta Psychologica, 54, 115-130.

Lacquaniti, F., Terzuolo, C. A., \& Viviani, P. (1984). Global metric properties and preparatory processes in drawing movements. In S. Kornblum \& J. Requin (Eds.), Preparatory states and processes (pp. 357-370). Hillsdale, NJ: Erlbaum.

Liberman. A. M., \& Mattingly, I. G. (1985). The motor theory of speech perception revisited. Cognition, 21, 1-36.

Lightfoot, D. (1987). The language lottery: Toward a biology of grammars Cambridge, MA: MIT Press.

Mach, E. (1897). Beiträge zur Analyse der Empfindungen [Contributions to the analysis of sensations]. La Salle, IL: Open Court. (Original work published 1885)

Mefferd, R. B., \& Wieland. B. A. (1967a). Perception of depth in rotating objects: 2 . Perspective as a determinant of stereokinesis. Perceptual and Motor Skills, 25, 621-628.

Mefferd, R. B., \& Wieland, B. A. (1967b). Perception of depth in rotating objects: 1. Stereokinesis and the vertical-horizontal illusion. Perceptual and Motor Skills, 25, 93-100.

Musatti, C. L. (1924). Sui fenomeni stereocinetici [On stereokinetic phenomena]. Archivio Italiano di Psicologia, 3, 105-120.

Philip. B. R. \& Fisichelli. V. R. (1945). Effect of speed of rotation and complexity on the reversals of apparent movement in Lissajou[s] figures. American Journal of Psychology, 58, 530-539.

Poincare, H. (1952). La science et l'hypothese [Science and hypothesis]. New York: Dover. (Original work published 1905)

Proffitt. D. R.. \& Gilden. D. L. (1989). Understanding natural dynamics. Journal of Experimental Psychology: Human Perception and Performance, 15, 384-393.

Restle. F. (1979). Coding theory of the perception of motion config- uration. Psychological Review, 86, 1-24

Runeson, S. (1974). Constant velocity-Not perceived as such. Psychological Research, 37, 3-23.

Runeson, S. (1975). Visual prediction of collision with natural and non-natural motion functions. Perception \& Psychophysics, 18 , $261-266$.

Scheerer, E. (1984). Motor theories of cognitive structure: A historical review. In W. Prinz \& A. F. Sanders (Eds.), Cognition and motor processes (pp. 77-97). Berlin: Springer-Verlag.

Scheerer, E. (1987). Muscle sense and innervation feelings: A chapter in the history of perception and action. In H. Heuer \& A. F. Sanders (Eds.), Perspective in perception and action (pp. 171-194). Hillsdale, NJ: Erlbaum.

Shepard, R. N. (1984). Ecological constraints on internal representation: Resonant kinematics of perceiving, imaging, thinking, and dreaming. Psychological Review, 91, 417-447.

Shiffrar, M., \& Freyd, J. J. (1990). Apparent motion of the human body. Psychological Science, 1, 257-264.

Sperling, G., Landy, S. L., Dosher, B. A., \& Perkins, M. A. (1989). Kinetic depth effect and identification of shape. Journal of Experimental Psychology: Human Perception and Performance, 15, 826840.

Todd, J. T. (1984). The perception of three-dimensional structure from rigid and nonrigid motion. Perception \& Psychophysics, 36 , 97-103.

Ullman, S. (1979). The interpretation of visual motion. Cambridge, MA: MIT Press.

Viviani, P. (1986). Do units of motor action really exist? In H. Heuer \& C. Fromm (Eds.), Generation and modulation of action patterns (pp. 201-206). Berlin: Springer-Verlag.

Viviani, P. (1990). Motor-perceptual interactions: The evolution of an idea. In M. Piattelli-Palmarini (Ed.), Golem Monograph Series I: Cognitive science in Europe. Issues and trends, 11-39.

Viviani, P., Campadelli, P., \& Mounoud, P. (1987). Visuo-manual pursuit tracking of human two-dimensional movements. Journal of Experimental Psychology: Human Perception and Performance, I3, 62-78.

Viviani, P., \& Cenzato, M. (1985). Segmentation and coupling in complex movements. Journal of Experimental Psychology: Human Perception and Performance, 11, 828-845.

Viviani, P., \& McCollum, G. (1983). The relation between linear extent and velocity in drawing movements. Neuroscience, 10, $211-$ 218.

Viviani, P., \& Mounoud, P. (1990). Perceptuo-motor compatibility in pursuit tracking of two-dimensional movements. Journal of Motor Behavior, 22, 407-443.

Viviani, P., \& Schneider, R. (1991). A developmental study of the relationship between geometry and kinematics in drawing movements. Journal of Experimental Psychology: Human Perception and Performance, 17, 198-218.

Viviani, P., \& Stucchi, N. (1989). The effect of movement velocity on form perception: Geometric illusions in dynamic displays. Perception \& Psychophysics, 46, 266-274.

Viviani, P., \& Stucchi, N. (1992). Motor-perceptual interactions. In J. Requin \& G. Stelmach (Eds.), Tutorials in motor behavior II (pp. 229-248). Amsterdam: Elsevier North-Holland.

Viviani, P., \& Terzuolo, C. (1982). Trajectory determines movement dynamics. Neuroscience, 7, 431-437.

von Hofsten, C. (1974). Proximal velocity change as a determinant of space perception. Perception \& Psychophysics, 15, 488-494.

Wallach, H., \& O'Connell, D. N. (1953). The kinetic depth effect. Journal of Experimental Psychology, 45, 205-217. 


\section{Appendix}

\section{Modulation of Stimulus Velocity}

We describe the procedure for specifying the kinematics of the stimuli. The trajectories of both ellipses and scribbles were defined by specific pairs of parametric equations $x=x(t)$ and $y=y(t)$. The analytic form of these equations reflects the procedure followed to define the trajectories (see text) and, as far as geometry is concerned, has no intrinsic relevance. In fact, a pair of equations $x=x_{\phi}(t)=$ $x(\phi(t))$ and $y=y_{\phi}(t)=y(\phi(t))$ is associated with any strictly monotonic differentiable function $\phi(l)$, which defines the same trajectory as the original pair. Of course, the equivalence does not extend to the kinematics of the resulting movement, for a different tangential velocity corresponds to each pair of functions $x_{\phi}$ and $y_{\phi}$. Under fairly mild conditions, we show that given a velocity gain function $K(t) \geq$ 0 and the parameters $\alpha \geq 0$ and $\beta$, there exists a unique choice of the function $\phi(t)$ such that the corresponding pair $\left(x_{\phi}, y_{\phi}\right)$ satisfies the $\beta$ power relation

$$
V(t)=K(t)\left(\frac{R(t)}{1+\alpha R(t)}\right)^{\beta}, \quad \alpha \geq 0, K(t) \geq 0,
$$

between radius of curvature $V(t)$ and tangential velocity $R(t)$. For any pair $\left(x_{\phi}, y_{\phi}\right)$, the quantities $V(t)$ and $R(t)$ appearing in Equation Al have the following expressions:

$$
V(t)=\sqrt{\left(d x_{\phi} / d t\right)^{2}+\left(d y_{\phi} / d t\right)^{2}}
$$

and

$$
R(t)=\frac{\left[\left(d x_{\phi} / d t\right)^{2}+\left(d y_{\phi} / d t\right)^{2}\right]^{3 / 2}}{\left|\left(d x_{\phi} / d t\right)\left(d^{2} y_{\phi} / d t^{2}\right)-\left(d y_{\phi} / d t\right)\left(d^{2} x_{\phi} / d t^{2}\right)\right|}
$$

By using the chain rule for the derivative of composite functions,

$$
\frac{d x_{\phi}}{d t}=\frac{d x}{d \phi} \cdot \frac{d \phi}{d t}, \quad \frac{d^{2} x_{\phi}}{d t^{2}}=\left(\frac{d \phi}{d t}\right)^{2} \frac{d^{2} x}{d \phi^{2}}+\frac{d x}{d \phi} \cdot \frac{d^{2} \phi}{d t^{2}}
$$

(and similar expressions for the $y$ component), we obtain after some easy calculations

$$
V(t)=\frac{d \phi}{d t} \sqrt{(d x / d \phi)^{2}+(d y / d \phi)^{2}}
$$

and

$$
R(t)=\frac{\left[(d x / d \phi)^{2}+(d y / d \phi)^{2}\right]^{3 / 2}}{\left|(d x / d \phi)\left(d^{2} y / d \phi^{2}\right)-(d x / d \phi)\left(d^{2} y / d \phi^{2}\right)\right|},
$$

where all derivatives with respect to $\phi$ are taken at $\phi=\phi(t)$. Inserting Equations $\mathrm{A} 5$ and $\mathrm{A} 6$ into Equation $\mathrm{A} 1$ and solving for $d \phi / d t$ yields
In the case of elliptic trajectories, we set

$$
x_{\phi}(t)=B_{\lambda} \sin (\phi(t)), \quad y_{\phi}(t)=B_{y} \cos (\phi(t)) .
$$

Remembering that $\alpha=0, K^{\prime}(t)=K=$ constant (see the Method section of Experiment 1) and that eccentricity $\Sigma$ is defined by $\Sigma=[1$ $\left.-\left(B_{y} / B_{x}\right)^{2}\right]^{1 / 2}$, Equation A7 can be simplified:

$$
\frac{d \phi}{d t}=\frac{K \cdot B_{x}^{2,-1}}{B_{i}^{\beta}}\left[1-\Sigma^{2} \sin ^{2}(\phi)\right]^{(3,-1) / 2} .
$$

This equation was integrated numerically with a standard RungeKutta routine. The choice of the integration step $\delta \tau$ was dictated by the condition that one complete cycle had to comprise exactly $M=$ 800 samples (see the Method section of Experiment 1). The condition was satisfied by using the following fact. Separating the variables, and integrating Equation A9 formally, it follows that the analytic solution $\phi$ is periodic, and the period is related to the velocity gain factor by the following equations:

$$
T=\frac{4 \Gamma(\beta, \Sigma)}{K} B_{x}^{1-2 \mu} B_{r}^{j}
$$

where

$$
\Gamma(\beta, \Sigma)=\int_{0}^{\pi / 2}\left[\left(1-\sin ^{2}(t)\right)^{(1-3 \otimes) / 2}\right] d t
$$

Thus, whatever the value of $K$, the required integration step is given by $\delta t=T / M$. Notice that $T$ is a computational variable and not the actual period of the stimuli expressed in seconds. The latter was dictated by the number of samples and by the rate at which they were displayed.

In the case of pseudorandom scribbles, we integrated Equation A7 directly over successive segments after setting

$$
x_{\phi}(t)=\sum_{k=1}^{4} A_{x k} \sin \left(2 \pi f_{k k} \phi(t)\right), \quad y_{\phi}(t)=\sum_{k=1}^{4} A_{y k} \sin \left(2 \pi f_{y k} \phi(t) .\right.
$$

Because it is impossible to derive an expression for $T$ that is analogous to Equation A10, however, we fixed an integration step, and we computed with an iterative algorithm the value of $K_{0}$ in the relation $K_{J}=K_{0} L^{b}$ such that a movement cycle was completed in the required

$$
\frac{d \phi}{d t}=\frac{K(t)\left[(d x / d \phi)^{2}+(d y / d \phi)^{2}\right]^{(3 / 3-1) / 2}}{\left\{\left|(d x / d \phi)\left(d^{2} y / d \phi^{2}\right)-(d y / d \phi)\left(d^{2} x / d \phi^{2}\right)\right|+\alpha\left[(d x / d \phi)^{2}+(d y / d \phi)^{2}\right]^{3 / 2}\right\}^{3}} .
$$

This is a separable, nonlinear differential equation of the first degree. By inserting the solution $\phi(t)$ into the general parametric equations $x_{\phi}$ and $y_{\phi}$, we finally obtain a movement that follows the desired trajectory and satisfies Constraint A1. Notice that the law of motion $s=s(t)$ is uniquely specified by $\phi(t): s(t)=\int_{0}^{t} V(t) d t$, where $V(t)$ is given by Equation $\mathrm{A} 2$. number of samples. In addition, in this case the actual period depended on the number of samples and the display rate.

Received September 17, 1990

Revision received July 10, 1991

Accepted July 10, 1991 